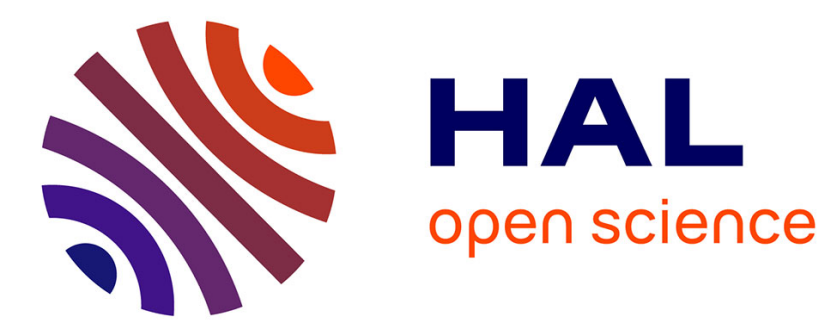

\title{
Reynolds, Mach, and Freestream Turbulence Effects on the Flow in a Low-Pressure Turbine
}

\author{
Maxime Fiore, Nicolas Gourdain
}

\section{To cite this version:}

Maxime Fiore, Nicolas Gourdain. Reynolds, Mach, and Freestream Turbulence Effects on the Flow in a Low-Pressure Turbine. Journal of Turbomachinery, 2021, 143 (10), pp.101009-1010022. 10.1115/1.4050919 . hal-03238795

\section{HAL Id: hal-03238795 \\ https://hal.science/hal-03238795}

Submitted on 27 May 2021

HAL is a multi-disciplinary open access archive for the deposit and dissemination of scientific research documents, whether they are published or not. The documents may come from teaching and research institutions in France or abroad, or from public or private research centers.
L'archive ouverte pluridisciplinaire HAL, est destinée au dépôt et à la diffusion de documents scientifiques de niveau recherche, publiés ou non, émanant des établissements d'enseignement et de recherche français ou étrangers, des laboratoires publics ou privés. 


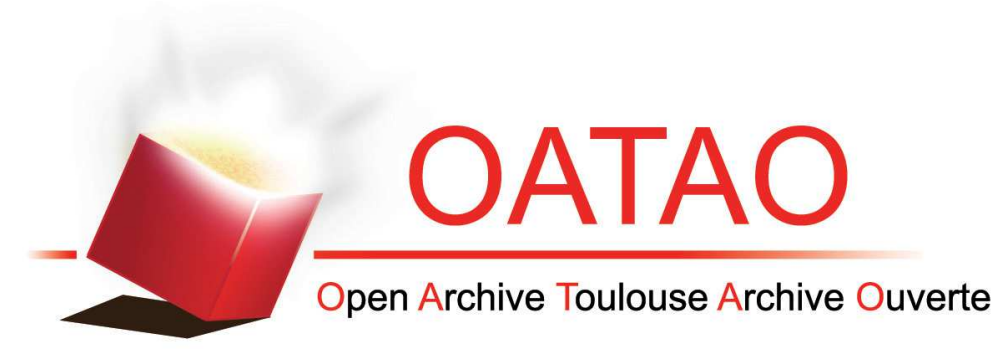

\section{Open Archive Toulouse Archive Ouverte (OATAO)}

OATAO is an open access repository that collects the work of some Toulouse researchers and makes it freely available over the web where possible.

This is an author's version published in: https://oatao.univ-toulouse.fr/27949

Official URL: http://doi.org/10.1115/1.4050919

\section{To cite this version :}

Fiore, Maxime and Gourdain, Nicolas Reynolds, Mach, and Freestream Turbulence Effects on the Flow in a LowPressure Turbine. (2021) Journal of Turbomachinery, 143 (10). 101009-1010022. ISSN 0889-504X

Any correspondence concerning this service should be sent to the repository administrator: tech-oatao@listes-diff.inp-toulouse.fr 


\section{Reynolds, Mach, and Freestream Turbulence Effects on the Flow in a Low-Pressure Turbine}

\section{Maxime Fiore ${ }^{1}$}

ISAE-Supaero,

Toulouse, France

e-mail: maxime.fiore@isae-supaero.fr

\section{Nicolas Gourdain}

DAEP,

ISAE-Supaero,

Toulouse, France

e-mail: nicolas.gourdain@isae-supaero.fr
This article presents the large-eddy simulation (LES) of a low-pressure turbine (LPT) nozzle guide vane (NGV) for different Reynolds (Re) and Mach (Ma) numbers with or without inlet turbulence prescribed. The analysis is based on a slice of an LPT blading representative of a midspan flow, where secondary flows, hub, and shroud effects are lower. The characteristic Re of the LPT can vary by a factor of four between take-off and cruise conditions. In addition, the LPT operates at different Ma values, and the incident flow can have significant levels of turbulence due to upstream blade wakes. This article investigates numerically using LES the flow around an LPT blading with three different Reynolds number $R e=175,000$ (cruise), 280,000 (mid-level altitude), and 500,000 (take-off) keeping the same characteristic Mach number Ma=0.2 and three different Mach number $M a=0.2,0.5$, and 0.8 keeping the same Reynolds number $R e=280,000$. These different simulations are performed with $0 \%$ freestream turbulence (FST) followed by inlet turbulence (6\% FST). The study focuses on the influence of these three parameters (Re, Ma, and upstream turbulence) on different flow characteristics: pressure distribution around the blade, near-wall flow behavior, loss generation, and turbulent kinetic energy (TKE) budget. The results show an earlier boundary layer separation on the aft region of the blade suction side when the Re is increased, while the increase of the Ma delays separation, similar to freestream turbulence. The TKE budget led on the different cases shows the predominant effect of the turbulent production and diffusion in the wake, the axial evolution of these different terms being relatively insensitive to Re and Ma. [DOI: 10.1115/1.4050919]

Keywords: low-pressure turbine, large-eddy simulation, Reynolds/Mach number effects, boundary layer, turbulent kinetic energy budget

\section{Introduction}

Low-pressure turbines (LPTs) experience Reynolds number (Re) variations typically consisting of the decrease by a factor of four between take-off and cruise [1-3] (400,000 against 100,000 for a wide-body gas turbine). Several studies have shown that $\mathrm{Re}$ effects may contribute to lower efficiencies at cruise conditions [4-6]. This parameter has a significant effect on the boundary layer state and transition processes. In particular, at low to moderate Re especially in altitude and for the last LPT stages, the suction side may generally be characterized by a large region where the boundary layer is laminar. Boundary layer separation may occur on the aft of the suction side in the adverse pressure gradient (APG) region. The separation can reattach leading to a turbulent boundary layer or be massively separated without reattachment resulting in large losses [7]. These phenomena are coupled with the wakes from upstream rows interacting with the suction side boundary layer of downstream blades and can lead to an early boundary layer transition and separation bubble canceling [8-11]. Upcoming LPT blading designs are oriented toward a decrease of the blade number [12] and stage spacing. However, higher APG is supposed to occur on the blade suction side, and boundary layer separation may increase [13]. The focus on the midspan flow to study Re effects may be a fair approximation since previous works have reported a strong impact of $\mathrm{Re}$ on profile losses and relatively weak on secondary [14,15] and tip leakage losses [16]. In conjunction with $\mathrm{Re}$ and upstream turbulence effects, the Mach number (Ma) can vary due to a change of the required load for the gas turbine and also affects the flow in the LPT. Due to the difficulty

\footnotetext{
${ }^{1}$ Corresponding author.
}

Contributed by the Heat Transfer Division of ASME for publication in the JouRNAL of Turbomachinery. Manuscript received November 24, 2020; final manuscript received March 25, 2021; published online May 17, 2021. Assoc. Editor: Paul Durbin. to reproduce real cruise conditions with ground test experimental facilities and detailed measurements, the effect of these three parameters has been widely investigated numerically.

In the past, Reynolds-averaged Navier-Stokes modeling approaches have been used to analyze transition processes and the onset of separation in LPT $[17,18]$. However, this was only possible based on additional developments like the one proposed by Jones and Launder [19] and the introduction of the turbulent kinetic energy (TKE) gradients in the so-called low-Reynolds number versions of the $\mathrm{k}-\epsilon$. This model allowed to capture transition without a dedicated transition model compared to the $\gamma-R e_{\theta}$ model developed by Menter et al. [20]. For sufficient grid and near-wall refinements, the large-eddy simulation (LES) approach [21] is able to handle the transition process of the boundary layer from a laminar to a turbulent regime [22] without additional modeling step. This methodology has been successfully used in predicting boundary layer transition [23-25] and in the LPT context [26-28]. LES provides a detailed time-dependent information about the important large-scale features of the flow and energy transfers with turbulence.

This article is devoted to study numerically the influence of $\mathrm{Re}$ and Ma on the flow around the blade of an LPT with or without inlet freestream turbulence (FST). The purpose is to better understand the influence of these three parameters on the main flow behavior, related losses and TKE budget. LES is used to simulate the flow around the midspan blade profile of a full three-dimensional configuration including hub, shroud, and cavities representative of an LPT cascade, extensively studied experimentally [29,30]. LPT Re ranges from about 50,000 in the last stages and high altitude conditions of small business jet engines to about 500,000 at take-off conditions in the first stages of the largest turbofans. Also, LPT usually operates at blade-relative exit flow $\mathrm{Ma}$ in the range 0.50.9 [8]. To account for these changes in $\mathrm{Re}$ and $\mathrm{Ma}$, three different Re values are studied: $\operatorname{Re}=175,000$ (cruise), 280,000 (mid-level 
altitude), and 500,000 (take-off) keeping the same characteristic Ma at a value of 0.2 . Also, three different Ma values are studied: $\mathrm{Ma}=$ $0.2,0.5$ and 0.8 keeping the same $\mathrm{Re}=280,000$. These cases are simulated in both $0 \%$ and $6 \%$ (FST) inlet conditions.

This article is organized as follows: in Sec. 2, the geometrical configuration, flow parameters, and the numerical method are described; in Sec. 3, the comparison against experiments is presented; and in Sec. 4, the near-wall flow behavior is detailed. Sections 5 and 6 are devoted to the analysis of the losses generated and the TKE budget. In each of these sections, the results are introduced for the mid-range $\mathrm{Re}$ and low Ma cases (R28M02, $\mathrm{R} 28 \mathrm{M} 02 \mathrm{~T}$ ), and then, the influence of $\mathrm{Re}$ and $\mathrm{Ma}$ is introduced in $0 \%$ and $6 \%$ FST, respectively.

\section{Computational Setup}

2.1 Configuration. The configuration under study represents the midspan geometry of a low Ma five nozzle guide vanes (NGV) linear cascade including hub, shroud, and cavities representative of an LPT investigated during the European Project MAGPI (2007-2011). The corresponding Re based on the blade suction side length is $\mathrm{Re}=500,000$ and the Ma based on the maximum suction side velocity is $\mathrm{Ma}=0.2$. This configuration has been tested with and without an inlet turbulence grid making possible to adapt the FST (either $0 \%$ or $6 \%$ FST). The details about the experimental facility, measurements, and data processing are provided in the study by Schuler et al. [29,30]. The simulation domain is composed of one blade representing the central blade of the five NGVs. The inlet is set one axial chord upstream of the leading edge (LE) and the outlet is set two axial chords downstream of the trailing edge (TE), leading to a simulation domain size of 4 axial chords. Figure 1 shows a cross-sectional view of the simulation domain with the main flow angles and characteristic dimensions of the domain gathered in Table 1 . The spanwise blade length is $h / C_{x}=$ 0.13 . This value is chosen based on previous LES/direct numerical simulation of LPT [2,31-33]. This assumption has been checked a posteriori by performing spanwise signal cross correlations (see Appendix A). The numerical simulations are first compared against the experimental data for both $0 \%$ and $6 \%$ FST at the Re and $\mathrm{Ma}$, respectively, considered in the experiments. Then, the cases are extended in $\mathrm{Re}$ and $\mathrm{Ma}$ to describe the effects of these two parameters.

2.2 Operating Points. The П-theorem [34] applied to the steady compressible flow around the considered blade without heat transfer shows that a reduced number of parameters can be

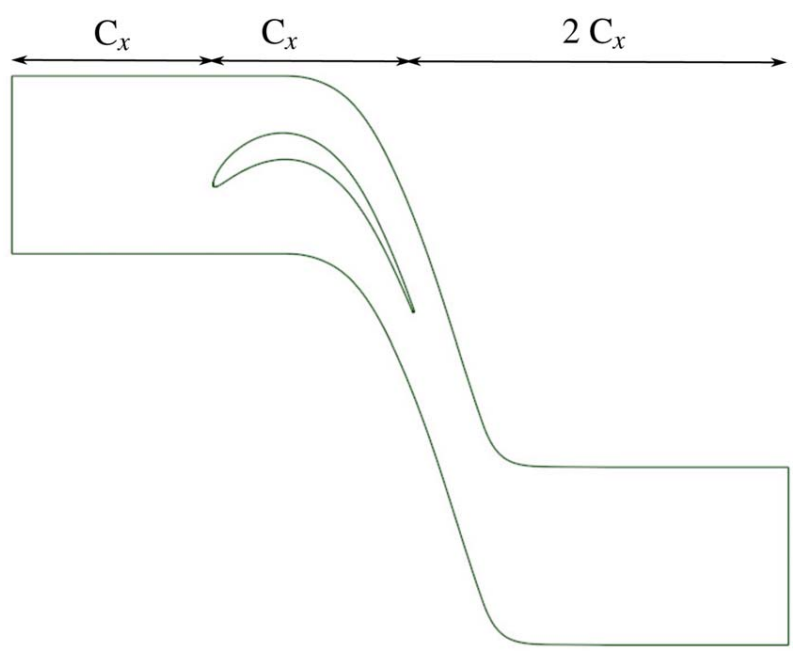

Fig. 1 Cross-sectional view of the computational domain
Table 1 Characteristics of the cascade rig

\begin{tabular}{llll}
\hline \hline Inlet blade angle $\alpha$ & $37.9 \mathrm{deg}$ & Outlet blade angle & $66.3 \mathrm{deg}$ \\
Axial chord $C_{x}$ & $75 \mathrm{~mm}$ & $h / C_{x}$ & 0.13 \\
Pitch/ $C_{x}$ & 0.884 & & \\
\hline \hline
\end{tabular}

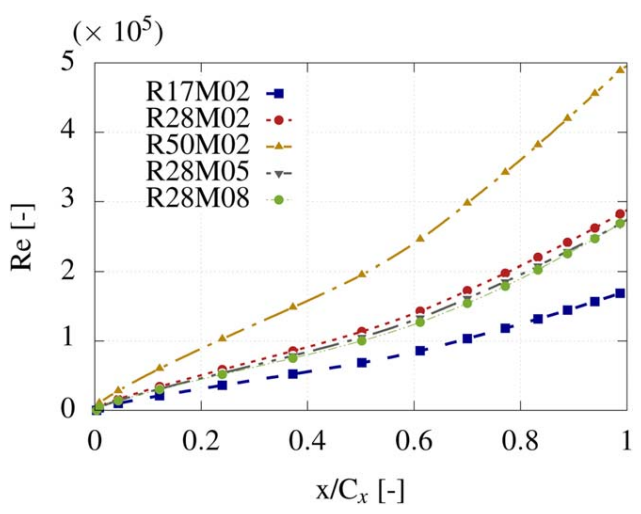

Fig. 2 Local suction side Re based on the velocity at the edge of the boundary layer and curvilinear abscissa for the $0 \%$ FST cases

used to describe the flow quantities in the cascade. These parameters reduce to $(\gamma, \operatorname{Pr}, \alpha, \operatorname{Ma}$, and $\operatorname{Re})$, where $\gamma, \operatorname{Pr}$, and $\alpha$ are the heat capacity ratio, the Prandtl number, and the incidence angle, respectively. In LPT, $\gamma$ and Pr variation are relatively low, such that for a fixed incidence angle $\alpha$, the flow quantities depend only on the $\mathrm{Re}$ in the incompressible limit and on ( $\mathrm{Re}, \mathrm{Ma})$ at higher Ma. The FST level is necessary to supplement the dimensional analysis in LPT. This parameter is particularly important since the incoming FST is generally nonnegligible due to upstream blade row interactions [35]. Furthermore, the Re in LPT lies in ranges where the boundary layer over the blade surface can remain fully laminar under no FST but can experience transition even at low FST levels [36,37].

A total of five simulations are performed: the first simulation at Re representative of a wide-body LPT at take-off $(\operatorname{Re}=500,000$, denoted R50M02), where experimental data are available; a second operating point corresponding to a medium altitude between take-off and cruise $(\mathrm{Re}=280,000$, R28M02); and a last operating point corresponding to cruise conditions at $10,000 \mathrm{~m}$ $(\mathrm{Re}=175,000, \mathrm{R} 17 \mathrm{M} 02)$, all three simulations keeping the same characteristic $\mathrm{Ma}=0.2$. Two additional simulations are performed keeping the same $\operatorname{Re}$ at a medium altitude $(\operatorname{Re}=280,000)$ but changing the characteristic Ma to a value of 0.5 (R28M05) and 0.8 (R28M08). Figures 2 and 3 show the evolution of the Re and

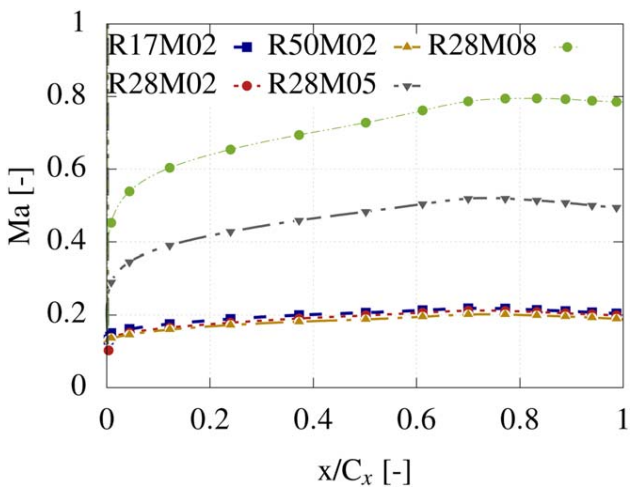

Fig. 3 Local suction side Ma based on the velocity and temperature at the edge of the boundary layer for the $0 \%$ FST cases 
Ma around the blade suction side based on the velocity, temperature at the edge of the boundary layer $u_{\text {edge }} T_{\text {edge }}$, and the curvilinear abscissa $\mathrm{c}: \operatorname{Re}(x)=u_{\text {edge }}(x) c(x) / \nu(x), \quad \operatorname{Ma}=u_{\text {edge }}(x) / \sqrt{\gamma r T_{\text {edge }}(x)}$. The boundary layer edge detection method used in the study to calculate the boundary layer characteristic quantities is based on a vorticity criterion similar to the method proposed and applied by Michelassi et al. [38]. The Re and Ma used to define different cases are based on the $\mathrm{Re}$ at the TE and the maximum Ma on the blade suction side for 0\% FST. Once the data have been extracted for these cases with $0 \%$ FST, inlet turbulence is used to simulate the cases with $6 \%$ FST at the blade leading edge. The inlet turbulence is imposed continuously in time over the inlet patch and differs from more realistic approaches based on incoming wakes methods $[2,26,32,39,40]$ that are more able to represent the wakes shedding process from upstream rows.

2.3 Meshing Strategy and Numerical Methods. The simulations are performed using the unstructured solver AVBP [41]. The blade surface discretization is based on triangles with equivalent edges lengths. The stream and spanwise characteristic mesh lengths at the wall $(\Delta x, \Delta z)$ are consequently the same. Over the blade surface discretization is generated a layer of 100 prisms in the wall-normal direction $\vec{y}$ to reduce nonorthogonality issues [42] and control neighboring cells expansion ratio compared to tetrahedral elements. The expansion ratio is set to 1.03 to guaranty 30 grid points in the viscous layer until $y^{+}=50$ for the most stringent case at $\mathrm{Re}=500,000$. The surface discretization and first off-wall grid point are set to fulfil recommendations for a wall-resolved LES [43-45] giving $50 \leq \Delta x^{+} \leq 80 ; \Delta y^{+} \leq 1$; and $15 \leq \Delta z^{+} \leq 25$. In the present mesh, this value has been set to reach $\Delta x^{+}, \Delta z^{+} \leq 25$, and $\Delta y^{+} \sim 1-2$ for the most stringent case at $\operatorname{Re}=500,000$ (see Fig. 4), leading to a mesh refinement similar to previous LES studies in LPT [39,46]. This near-wall mesh refinement remains coarser compared to highly resolved LES where recommendations are rather set around $\Delta x^{+} \leq 10, \Delta z^{+} \leq 7$ [47]. Tetrahedra fill the remaining simulation domain. The mesh size in the wake region is designed based on distributions of the Kolmogorov scale $\eta=\left(\nu^{3} / \epsilon\right)^{1 / 4}$, where $\epsilon$ is the local isotropic dissipation obtained assuming that the production of residual kinetic energy equals this quantity [48]. The mesh is designed to satisfy the condition $(\Delta x \Delta y \Delta z)^{1 / 3}<15 \eta\left(0.002 C_{x}\right)$ to capture the majority of the turbulent wake structures, leading to a mesh of $100 \times 10^{6}$ cells. A mesh dependency is proposed in Appendix B.

Periodic boundary conditions are applied on both lateral, top, and bottom surfaces of the simulation domain. The blade is treated as an adiabatic nonslipping surface. In the experiments, the R50M02 case has been tested with and without an upstream turbulence grid. Total pressure, temperature, and incident angle are imposed based on experimental data at the inlet of the domain. The turbulent flow generated by the grid is handled in the simulation by the use of a synthetic eddy viscosity method proposed in the study by Smirnov et al. [49] generating velocity fluctuations and coupled with the inlet condition. The integral length scale is set to $\Delta x / C_{x}=10^{-1}$

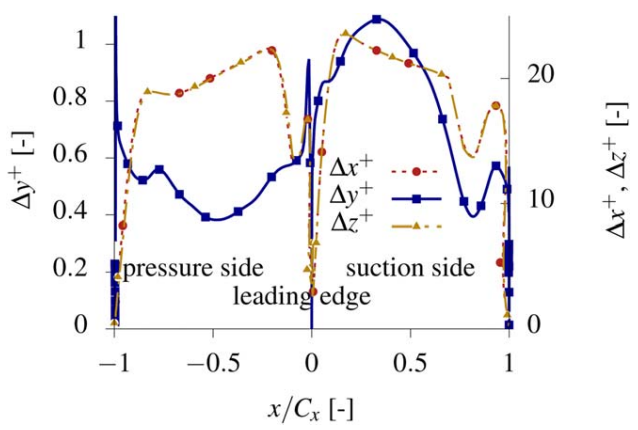

Fig. 4 Grid dimension at the blade wall for the R50M02 case

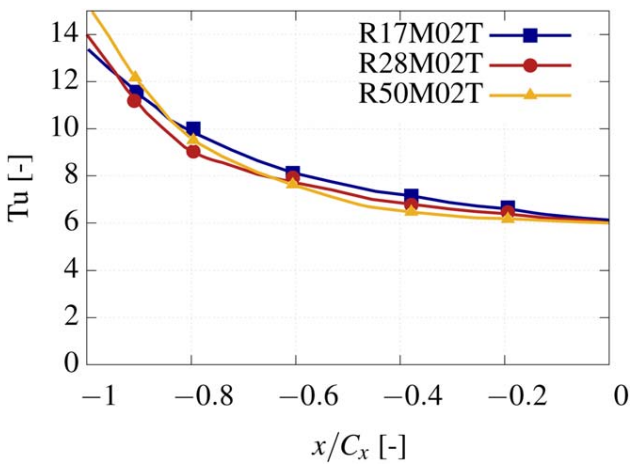

Fig. 5 Turbulence intensity decay from the inlet of the domain to the blade LE for the $6 \%$ FST

based on a similar grid and distance to the cascade [50] and numerical calibrations from the study by Troth [51]. The turbulence intensity $\mathrm{Tu}$ at the blade $\mathrm{LE}$ is $\mathrm{Tu}=6 \%$ based on experimental measurements. The cutoff length scale is set to $\Delta x / C_{x}=10^{-2}$ and corresponds to the characteristic length scale of the mesh from the inlet to the blade LE. The turbulence spectrum is based on the one proposed by Passot and Pouquet [52]. Figure 5 shows the turbulence intensity decay from the inlet of the domain in $x / C_{x}=-1$ to the blade LE $x / C_{x}=0$ obtained by integrating the velocity and velocity fluctuations on axial planes. The turbulent fluctuations injected at the inlet of the domain have been set to $\mathrm{Tu}=15 \%$ for the R50M02T case and marginally less for the lower Re cases to reach the turbulence level at the blade LE measured experimentally $\mathrm{Tu}=6 \%$. The value of the turbulence intensity has been checked for the different cases by setting a probe upstream of the blade leading edge. The static pressure based on the experiments is imposed at the outlet of the domain. Inlet and outlet boundaries are coupled with a Navier-Stokes characteristics boundary condition [12]. At 0\% FST, there may still be numerical noise present in the freestream due to spurious wave reflections, but these boundaries are intended to reduce this effect.

The convective operator is discretized by the two-step TaylorGalerkin scheme [53] (third-order accurate) to better resolve smallsized scales compared to the second-order accurate Lax-Wendroff scheme [54] also available in AVBP. The time discretization is based on a third- order accurate explicit time advancement scheme. The Courant-Friedrichs-Lewy number is set to 0.7 leading to a simulation time-step around $\Delta t^{+}=\Delta t\left\{u_{i n} / C_{x}=5 \times 10^{-6}\right.$ for the R28M08 case. The subgrid-scale model is the wall-adapting local eddy viscosity [55]. In all the simulations, the flow developed for ten characteristic flow-through periods of time $\Delta t_{\mathrm{FTP}}=4 C_{x} / u_{\text {in }}=7.5 \times 10^{-3}$. After this start-up period, the convergence of mean, first, and second-order moments of the flow were checked based on the signal of probes set in the blade boundary layer and in the wake. The temporal averaging used to build the mean flow field and TKE balance was performed over ten full characteristic periods $\Delta t_{\mathrm{FTP}}$ based on 800 flow solutions evenly spread and stored on the fly during the simulations.

\section{Mean Flow Field}

The pressure coefficient around the blade $C_{p}$ is defined as follows:

$$
C_{p}=\frac{p_{\text {tot,in }}-p}{p_{\text {tot,in }}-p_{\text {out }}}
$$

where $p_{\text {tot,in }}, p$, and $p_{\text {out }}$ are, respectively, the total pressure at the inlet, the static pressure around the blade, and the static pressure at the outlet of the domain. Experimental results are available for the R50M02 case without and with the turbulence grid between $x / C_{x}=0$ and 0.8 . Based on the experimental reports, no experimental data are available between $x / C_{x}=0.8$ and 1.0 since the trailing edge is thin and it becomes difficult to install pressure taps. 


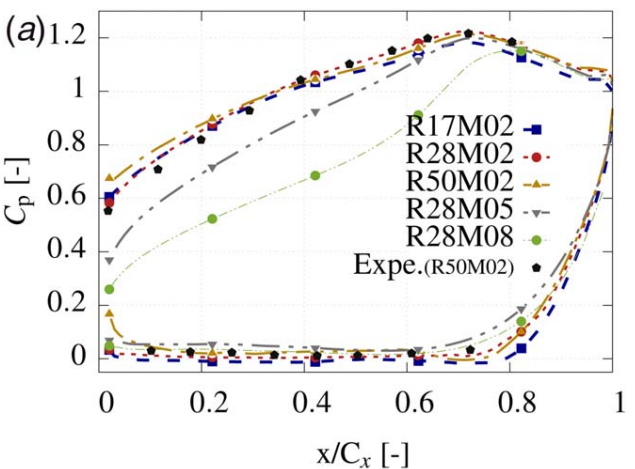

(b)

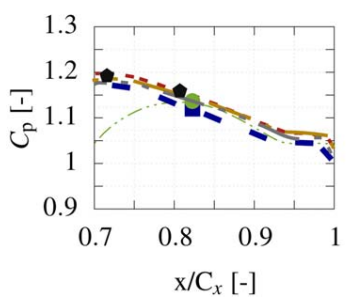

Fig. 6 (a) Pressure coefficient around the blade and (b) inset view close to the TE for the $0 \%$ FST cases

Figure 6 shows the pressure distribution around the blade for the different cases at 0\% FST. On the blade suction side, the flow accelerates in the favorable (negative) pressure gradient (FPG) region until $x / C_{x}=0.7$ and then decelerates until the TE on the aft region of the blade where the APG occurs. A discrepancy between the experiments and LES occurs in the FPG region starting from the LE. Variations of the incident angle have been tested without improving the matching between the experiments and the numerical simulation. The different cases show a region of constant pressure coefficient at the TE $\left(x / C_{x}=0.9\right)$, indicating a laminar separation bubble. Except close to the LE, the pressure coefficient around the blade obtained numerically shows a good agreement with the experiments in the FPG region where measurements are available with a maximum discrepancy of around $2 \%$. On the blade pressure side, the pressure coefficient is almost constant until $x / C_{x}=0.7$ before to increase in the FPG region until the TE. Figure 7 shows an instantaneous iso Q-criterion for the R28M02T. A pair of counter-rotating structures can be observed on the pressure side. $\mathrm{Wu}$ and Durbin [33] evidenced the presence of elongated structures close to the trailing edge on the pressure side most likely corresponding to a forced response to the incident wake. Vortices are also generated earlier on the pressure side, characterizing a possible separation bubble. Figure 8 shows the friction coefficient on the blade pressure side $C_{f}=\tau_{w} /\left(0.5 \rho u^{2}\right)$ at $0 \%$ FST, where $\tau_{\mathrm{w}}$ is the mean wall-shear stress. For the R17M02, R28M02, and R50M02 cases, the friction coefficient is negative between $x / C_{x}=0.2$ and $x / C_{x}=0.5$, characterizing the size of the pressure side separation bubble. For the R28M05 and R28M08 cases, the separation bubble lies between $x / C_{x}=0.15$ and $x / C_{x}=0.4$.

The pressure coefficient on the blade suction side marginally increases with the increase of the Re. For the same boundary layer state, Michelassi et al. [11] also observed a low sensitivity of the pressure coefficient on the blade suction side of an LPT at lower $\operatorname{Re}=60,000$ and $\operatorname{Re}=100,000$. The region of the constant pressure coefficient on the aft of the blade can be observed for the different $\mathrm{Re}$ values at a similar position. On the blade pressure side, the region of constant pressure coefficient is marginally modified by a variation of the $\operatorname{Re}$ as observed on the friction coefficient.

The increase of the Ma at a constant Re has a marginal influence on the pressure coefficient around the blade pressure side with a recompression initiated earlier $\left(x / C_{x}=0.6-0.65\right)$. On the blade suction side, the pressure coefficient is decreased with an increased Ma. Also the position of the throat is moved toward the TE with a lower size of the APG region at the rear of the blade. The region of the constant pressure coefficient characterizing the laminar separation bubble remains for the different Ma.

Figure 9 shows the pressure coefficient around the blade for the $6 \%$ FST cases. For the cases with 6\% FST, the influence of the Re and $\mathrm{Ma}$ on the pressure coefficient around the blade is similar compared to the $0 \%$ FST cases. However, on the aft of the blade pressure side, the compression is initiated earlier for different operating points, indicating a possible decrease of the dead-region size associated with the pressure side separation bubble. On the blade suction side, a larger pressure deficit is observed in the numerical simulation and experiments for the $6 \%$ FST compared to the $0 \%$ FST. Also, the region of constant pressure coefficient on the aft region of the blade suction side is canceled at $6 \%$ FST.

The second quantity available in the experiments is the pressure loss coefficient $25 \% C_{x}$ downstream of the blade TE denoted $\zeta$ and is defined as follows:

$$
\zeta=\frac{p_{\text {tot, in }}-p_{\text {tot, } 25 \%}}{p_{\text {tot, } 25 \%}-p_{25 \%}}
$$

where $p_{25 \%}$ and $p_{\text {tot, } 25 \%}$ are the static and total pressure $25 \% C_{x}$ downstream of the blade TE. Table 2 presents the pressure loss coefficient $25 \% \quad C_{x}$ downstream of the blade TE for the R50M02T case (6\% FST) based on the experiments, the LES with $0 \%$ FST, and the LES with $6 \%$ FST. The LES with $0 \%$ FST largely underestimates the pressure losses compared to the

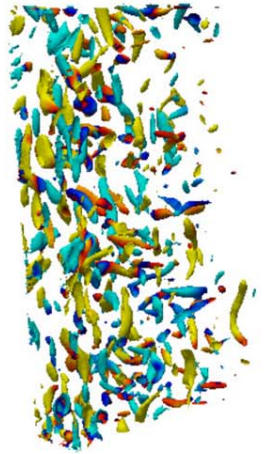

Inlet turbulence

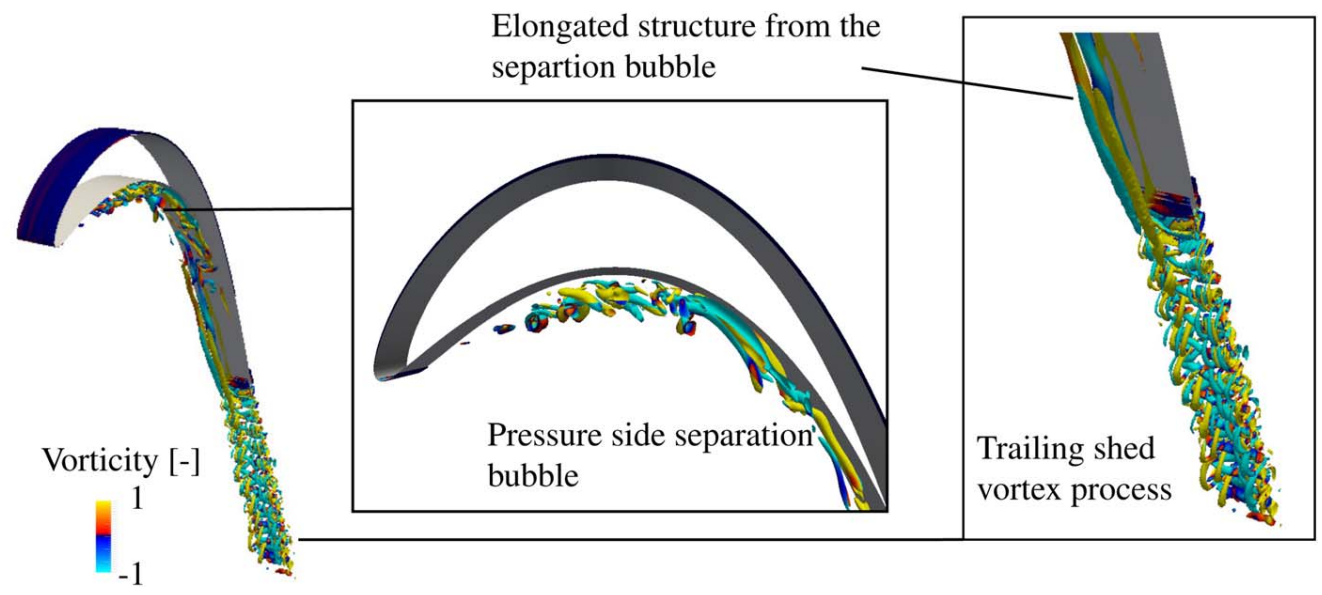

Fig. 7 Iso $Q$-criterion $Q=10^{7}$ colored by the vorticity for the R28M02T case in the first time-steps of the prescribed inlet turbulence 


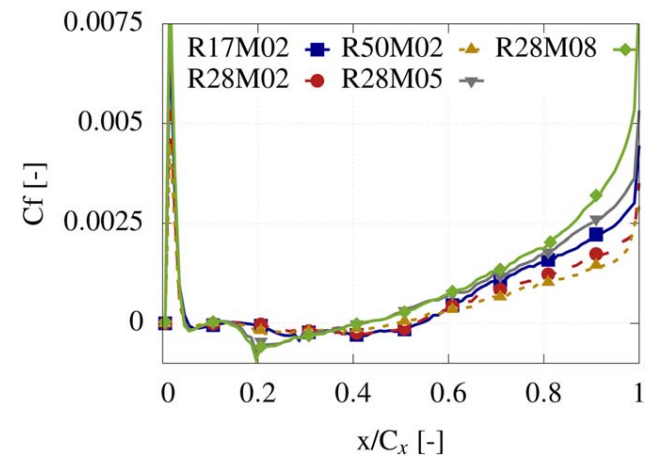

Fig. 8 Friction coefficient $C_{f}$ on the blade pressure side for the $0 \%$ FST cases

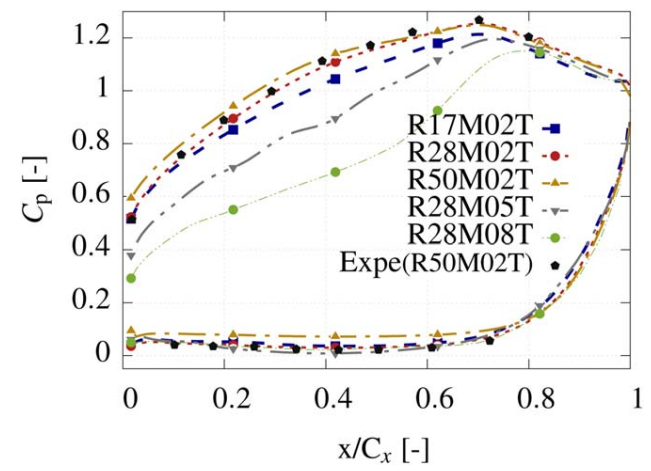

Fig. 9 Pressure coefficient around the blade with 6\% FST

Table 2 Pressure loss coefficient $25 \% C_{x}$ downstream of the blade TE for the R50M02T case (6\% FST)

\begin{tabular}{cccc}
\hline & Experiment 6\% FST & LES 0\% FST & LES 6\% FST \\
\hline$\zeta(-)$ & 0.0414 & $0.0287(-30.6 \%)$ & $0.0398(-3.8 \%)$ \\
\hline \hline
\end{tabular}

experiments (-31.3\%). The LES with 6\% FST shows a lower discrepancy of $3.8 \%$ and is in good agreement with the experiments. This observation gives more confidence in the use of the LES simulations with $6 \%$ FST for the cases with the turbulence grid despite there is still some issues close to the LE for the pressure coefficient around the blade.

\section{Near-Wall Flow}

The boundary layer velocity profile on the blade suction side at $50 \%$ blade chord for the 0\% FST is shown in Fig. 10. For the R28M02 case, the boundary layer velocity profile fits the Blasius boundary layer profile. Figure 11 shows the shape factor $H=\delta_{1}^{*} / \theta$ on the blade suction side for the $0 \%$ FST cases, where $\delta_{1}^{*}$ and $\theta$ are the boundary layer displacement and momentum thickness. The shape factor is close to $H=2.59$ on the FPG region of the suction side until $x / C_{x}=0.7$ and confirms the development of a laminar boundary layer. Downstream of the throat $\left(x / C_{x}=0.7\right)$, the boundary layer experiences an APG at the edge of the boundary layer nondimensionalized with the Clauser pressure gradient parameter $\beta=\delta_{1}^{*} / \tau_{w}\left(d p_{\text {edge }} / d x\right)$, where $\left(d p_{\text {edge }} / d x\right)$ is the gradient of pressure at the boundary layer edge in the direction tangent to the blade surface. This parameter, negative in the FPG region becomes positive downstream of the throat on the blade suction side characterizing the APG (see Fig. 12). On

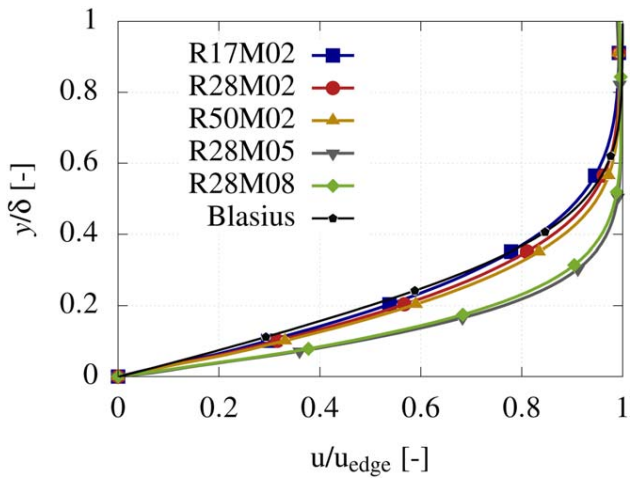

Fig. 10 Suction side boundary layer velocity profile in the FPG region at mid chord $\left(x / C_{x}=0.5\right)$ for the $0 \%$ FST cases

the aft region of the blade, the APG reduces the momentum in the near-wall region characterized by an increase of the shape factor. Figure 13 shows the friction coefficient $C_{f}$ at the blade suction side wall for the $0 \%$ FST cases. The friction coefficient is initially positive corresponding to a fully attached boundary layer until $x / C_{x}=0.9$ and then becomes negative, indicating a boundary layer separation. This observation is also supported by the region of constant pressure coefficient on the blade suction side at this same location. For the 6\% FST cases, the shape factor $\mathrm{H}$ around the blade suction side is shown in Fig. 14. At the lowest $\operatorname{Re}(\mathrm{R} 17 \mathrm{M} 02 \mathrm{~T})$, the shape factor distribution is similar to the case with $0 \%$ FST. For other cases at higher Re (R28M02T, R28M05T, R28M08T, and R50M02T), the shape factor reaches values around 1.4 close to the LE, indicating a

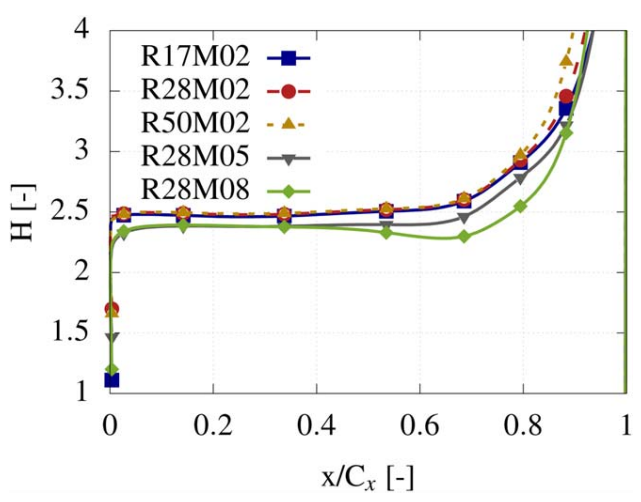

Fig. 11 Shape factor $\mathrm{H}$ on the blade suction side for the $0 \%$ FST cases

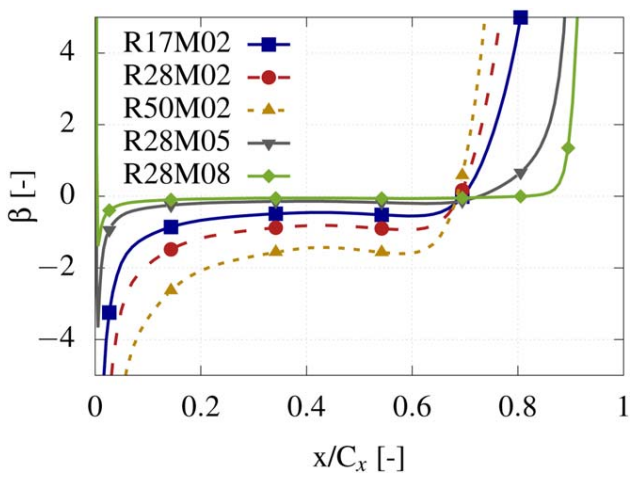

Fig. 12 Clauser pressure gradient parameter $\beta$ on the blade suction side for the $0 \%$ FST cases 


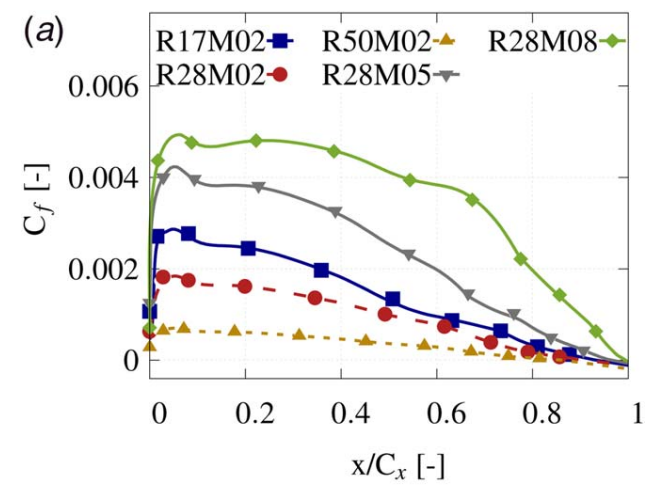

(b)

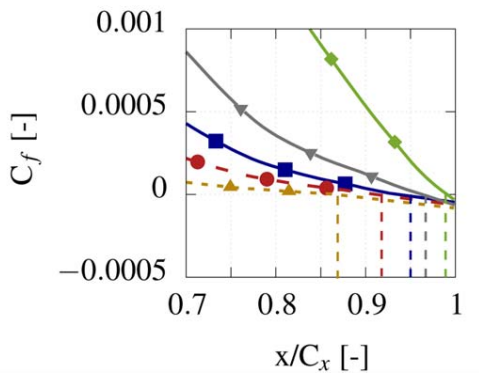

Fig. 13 (a) Friction coefficient $C_{f}$ on the blade suction side and (b) inset view close to the TE for the $0 \%$ FST cases

turbulent boundary layer. The FST induces the transition to a turbulent state of the boundary layer originally laminar for the mid and high Re cases. For the R17M02T case, a transition toward a turbulent state of the suction side boundary layer could be expected based, for example, on the works of Mayle [56]. The author showed that in the gas turbine, it is common to see transitional flows as soon as a local $\mathrm{Re}=50,000$ in some high FST cases. As well, Abu-Ghannam and Shaw [57] showed that over a flat plate, with an FST of 6\%, the boundary layer may start to transition at around $\mathrm{Re}=50,000$ and end the transition at around $\mathrm{Re}=150,000$. The different parameters of this simulation have been thoroughly checked, and according to the authors, this flow behavior may indicate a Re effect, i.e., the characteristic Re is around 50,000 at midspan, and depending on the FST characteristics, the boundary layer may still be laminar or transitional. Gourdain [58] observed a laminar-to-turbulent transition on the rotor blade of a compressor at around $40 \%$ chord and relatively higher $\operatorname{Re}=700,000$ with $2 \%$ inlet turbulence intensity. The relatively higher turbulence intensity in this configuration $(\mathrm{Tu}=6 \%)$ may promote the early transition close to the LE for the two highest $\mathrm{Re}$ considered. This may be also confirmed in the

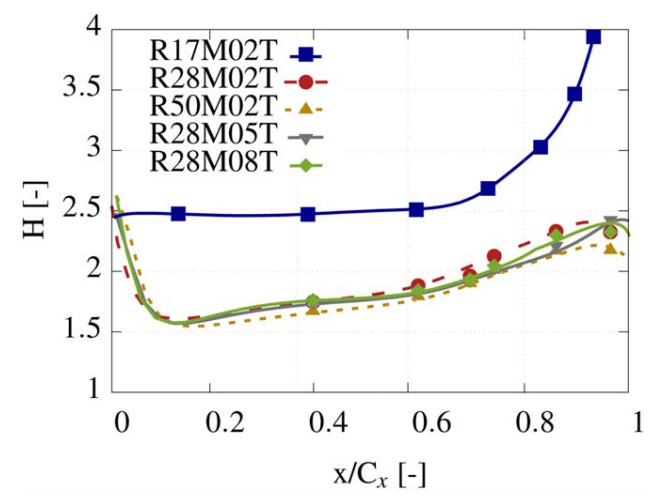

Fig. 14 Shape factor $\mathrm{H}$ on the blade suction side for the $6 \%$ FST cases experiments since the levels of pressure coefficient until the throat are higher for the R28M02T compared to the R28M02 (see Figs. 6 and 9).

When the Re is modified at a constant Ma for the $0 \%$ FST cases (R17M02, R28M02, and R50M02), the boundary layer velocity profile at $x / C_{x}=0.5$ on the blade suction side is marginally modified. This observation is supported by the insensitivity of the shape factor to the characteristic Re on the FPG region. On the rear region of the blade suction side, when the Re is increased, the axial pressure gradient $\beta$ is increased. The main effect is a decrease of the friction coefficient $C_{f}$ for a considered spatial location at the rear of the blade. As a consequence, when the characteristic Re is increased, the boundary layer is more prone to separate. In LPT, an increase of the Re is generally able to cancel the potential boundary layer separation by a transition process at sufficiently high $\mathrm{Re}$, making the boundary layer less prone to separate. However, based on these observations, when the boundary layer is maintained laminar on the aft region of the blade, the increase of the characteristic $\mathrm{Re}$ increases the potential for an early boundary layer separation. For the $6 \%$ FST cases, in the FPG of the blade until $x / C_{x}=0.2$, the increase of the $\mathrm{Re}$ induces additional momentum close to the wall since the shape factor decreases compared to the $0 \%$ FST cases, characterizing the turbulent boundary layer with more momentum in the near-wall region.

For the $0 \%$ FST cases, the increase of the Ma at a constant Re (R28M02, R28M05, and R28M08) shows that more momentum is provided close to the suction side wall based on the boundary layer velocity profiles at $x / C_{x}=0.5$. This observation is confirmed with the decrease of the shape factor on the FPG region. The increase of the Ma reduces the effect of the axial pressure gradient at the edge of the boundary layer. This indicates that at higher $\mathrm{Ma}$, the suction side boundary layer is less prone to separate on the aft region of the blade and promotes a stabilizing effect at constant Re. Muppidi and Mahesh [59] also observed a stabilizing effect of an increased $\mathrm{Ma}$ for the flow over a flat plate with roughness in the supersonic range. For the 6\% FST cases, the increase of the Ma induces a marginal velocity deficit in near-wall region characterized by an increase of the shape factor. On the rear region of the suction side, similar to the $0 \%$ FST cases, the shape factor increases due to the adverse pressure gradient lifting off the boundary layer velocity profile from the wall. Compared to the $0 \%$ FST simulations with a laminar boundary layer on the suction side, the increase of the shape factor is more moderate. Figure 15 shows the friction coefficient around the blade suction side for the $6 \%$ FST cases. The friction coefficient remains marginally positive on the aft of the suction side and indicates that the boundary layer remains attached until the TE. Michelassi et al. [2] observed a similar decrease of the potential boundary layer separation on the aft region of an LPT at lower $\operatorname{Re}(60,000$ and 100,000$)$ with turbulent wake impinging the blade.

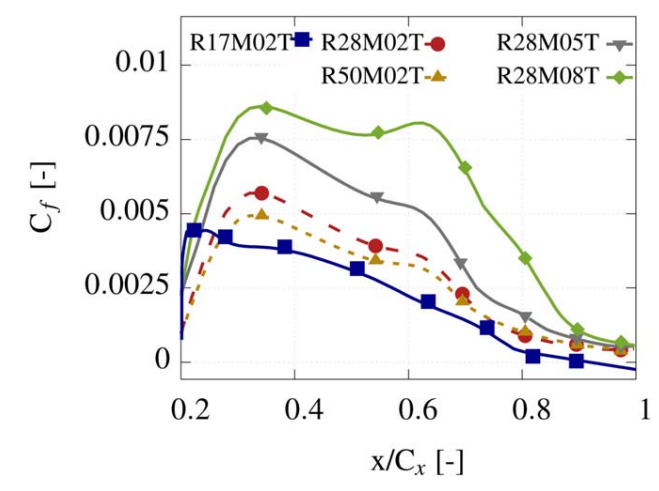

Fig. 15 Friction coefficient $C_{f}$ on the blade suction side for the $6 \%$ FST cases 


\section{Losses}

The viscous losses generated in the LPT cascade can be split into a mean flow and a turbulent contribution. In LES, the splitting can be obtained by taking advantage of the unsteady nature of the method. The total viscous irreversibilities produced $\Phi_{\nabla u}$ can be written as follows [32,60-63]:

$$
\Phi_{\nabla u}=\Phi_{\nabla u, \text { mean }}+\mathscr{P}_{k}
$$

where $\Phi_{\nabla u \text {,mean }}$ is the mean viscous dissipation and $\mathscr{P}_{k}$ is the TKE production term. These different contributions can be expressed as follows:

$$
\begin{gathered}
\Phi_{\nabla u, \text { mean }}=\iiint_{\mathcal{V}}\left(\mu+\mu_{\mathrm{SGS}}\right)\left(\frac{\partial\left[u_{i}\right]}{\partial x_{j}}+\frac{\partial\left[u_{j}\right]}{\partial x_{i}}\right) \frac{1}{\bar{T}} \frac{\partial\left[u_{i}\right]}{\partial x_{j}} d \mathcal{V} \\
\mathscr{P}_{k}=\iiint_{\mathcal{V}}-\left\langle\bar{\rho} u_{i}^{\prime} u_{j}^{\prime}\right\rangle \frac{\partial\left[u_{i}\right]}{\partial x_{j}} d \mathcal{V}
\end{gathered}
$$

where the overbar - denotes the filtered quantity as an output of the LES. The tilde ? denotes a quantity calculated from the filtered variables $\bar{\rho}, \overline{\rho u_{i}}$, and $\bar{p}$. Thus, the calculated velocity is $\tilde{u}_{i}=\overline{\rho u_{i}} / \bar{\rho}$ using Favre filtering. The statistical averaging is denoted by

$\langle$.$\rangle and Favre averaging by [.], yielding to \left[u_{i}\right]=\left\langle\rho u_{i}\right\rangle /\langle\rho\rangle$ for instance. The fluctuating velocity is defined by $u_{i}^{\prime}=\tilde{u}_{i}-\left[u_{i}\right]$.

The accumulated mean viscous dissipation from the blade LE to $25 \% C_{x}$ downstream of the blade for the $0 \%$ FST cases is shown in Fig. 16. The mean viscous dissipation increases linearly along the blade with a larger slope from $x / C_{x}=0.5$ until the TE corresponding to more losses generated on the rear region of the blade. The viscous dissipation is associated with the boundary layer developing over the blade suction and pressure sides and inducing velocity gradients in the near-wall region. Behind the TE $\left(x / C_{x}=1\right)$, the accumulated mean viscous dissipation remains constant and indicates that almost all mean viscous losses are generated along the blade.

The increase of the Re induces less mean viscous dissipation for the $0 \%$ FST cases. As stated, the boundary layer velocity profiles for the three different Re matches well. When the Re increases, the boundary layer thickness decreases as shown in Fig. 17, and less mean viscous dissipation is generated.

The increase of the Ma at 0\% FST induces more mean viscous dissipation. The boundary layer thickness marginally decreases when the Ma is increased, but, as stated, the increase of the Ma produces boundary layer velocity profiles with more momentum in the near-wall region and consequently more mean viscous dissipation occurs.

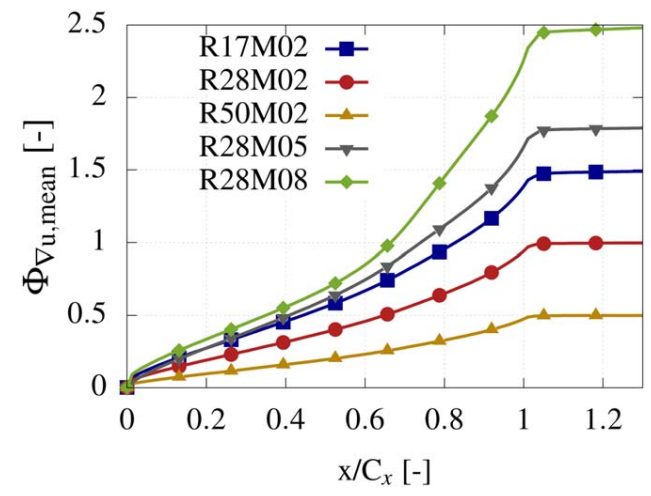

Fig. 16 Accumulated mean viscous dissipation along the simulation domain for the $0 \%$ FST cases

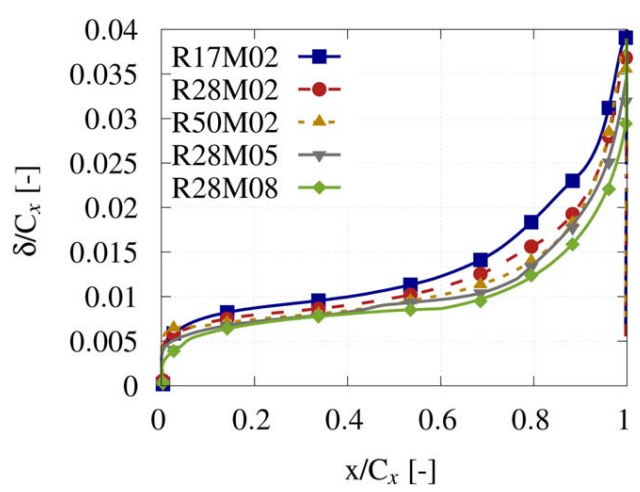

Fig. 17 Boundary layer thickness on the blade suction side for the $0 \%$ FST cases

Figure 18 shows the TKE production in the wake region for the $0 \%$ FST cases. The increase of TKE production is sharp between $x / C_{x}=1$ and 1.05 , where almost all the TKE production is performed. This trend is similar for the different $\mathrm{Re}$ and Ma values. In terms of loss level, a decrease of the Re promotes more TKE production and an increase of the Ma promotes more TKE production. This dependence of TKE production to $\mathrm{Re}$ and $\mathrm{Ma}$ is similar to the mean viscous dissipation, and the balance of losses between mean viscous dissipation and TKE production remains almost constant for the different cases studied $(60 \%$ of losses induced by mean dissipation and $40 \%$ due to TKE production).

Figure 19 shows the accumulated mean viscous dissipation along the simulation domain for the $6 \%$ FST cases. The mean viscous dissipation increases for the different cases except for the low Re case (R17M02T). The influence of the Re and Ma values is similar to the $0 \%$ FST except the level of losses considerably higher. Figure 20 shows the boundary layer thickness for the 6\% FST cases. For the cases at medium and high Re and 6\% FST, the boundary layer is thicker compared to the $0 \%$ FST cases, and the velocity profiles have more momentum close to the wall due to the turbulent nature of the boundary layer. The corresponding mean viscous dissipation is higher compared to the $0 \%$ FST cases with laminar boundary layers. Figure 21 shows the accumulated TKE production along the blade and in the wake for the 6\% FST cases. Except for the low $\mathrm{Re}$ case (R17M02T), the TKE production is initiated close to the LE and then increases moderately until the TE of the blade. A large increase is observed downstream in the wake region.

\section{Turbulent Kinetic Energy Budget}

The influence of Re, Ma, and incoming FST can be assessed on the different terms of the TKE balance $\langle\bar{\rho}\rangle k=\left\langle\bar{\rho} u_{i}^{\prime 2} / 2\right\rangle$, which can be

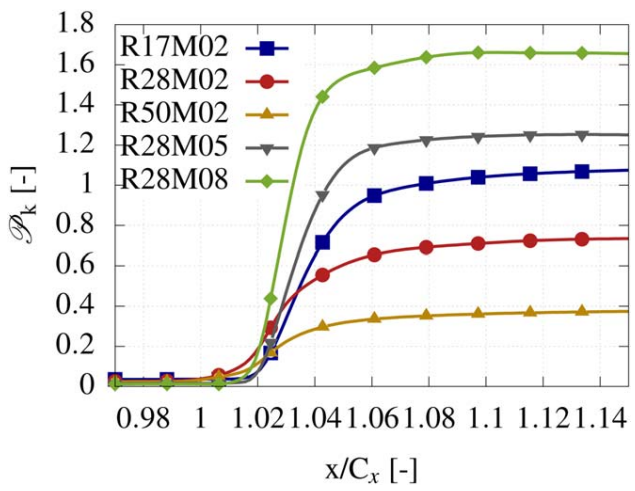

Fig. 18 Accumulated TKE production in the wake region for the $0 \%$ FST cases 


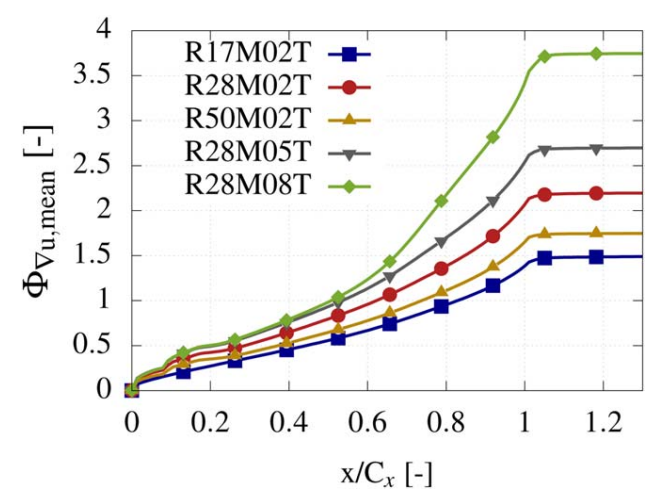

Fig. 19 Accumulated mean viscous dissipation along the simulation domain for the $6 \%$ FST cases

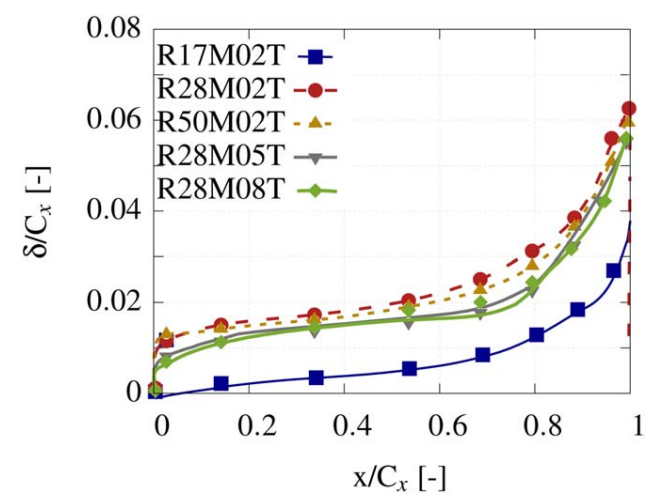

Fig. 20 Boundary layer thickness on the blade suction side for the $6 \%$ FST cases

written as follows $[48,64]$ :

$$
\begin{aligned}
& \underbrace{\frac{\partial}{\partial x_{j}}\left(\frac{1}{2}\left\langle\bar{\rho} u_{i}^{\prime 2}\right\rangle\left[u_{j}\right]\right)}_{\text {Mean flow TKE convection }}=\underbrace{-\left\langle\bar{\rho} u_{i}^{\prime} u_{j}^{\prime}\right\rangle \frac{\partial\left[u_{i}\right]}{\partial x_{j}}}_{\text {Production } \mathscr{P}_{\mathrm{k}}} \underbrace{-\frac{1}{2} \frac{\partial}{\partial x_{j}}\left\langle\bar{\rho} u_{i}^{2} u_{j}^{\prime}\right\rangle}_{\text {Turbulence diffusion }} \\
& \underbrace{-\frac{\partial}{\partial x_{i}}\left\langle p^{\prime} u_{i}^{\prime}\right\rangle}_{\text {Pressure diffusion Press.-dilatation }}+\underbrace{\left\langle p^{\prime} \frac{\partial u_{i}^{\prime}}{\partial x_{i}}\right\rangle}_{\text {velo. gradp. Viscous dissipation } \varepsilon}-\underbrace{\left\langle u_{i}^{\prime}\right\rangle \frac{\partial\langle\bar{p}\rangle}{\partial x_{i}}} \underbrace{\left\langle\tilde{\tau}_{i j} \frac{\partial u_{i}^{\prime}}{\partial x_{j}}\right\rangle}
\end{aligned}
$$

Before to build the TKE balance, the convergence of the simulations has been first checked by monitoring the first- and second-order statistics convergence of probes set in the blade boundary layer and in the wake. The different terms of the TKE

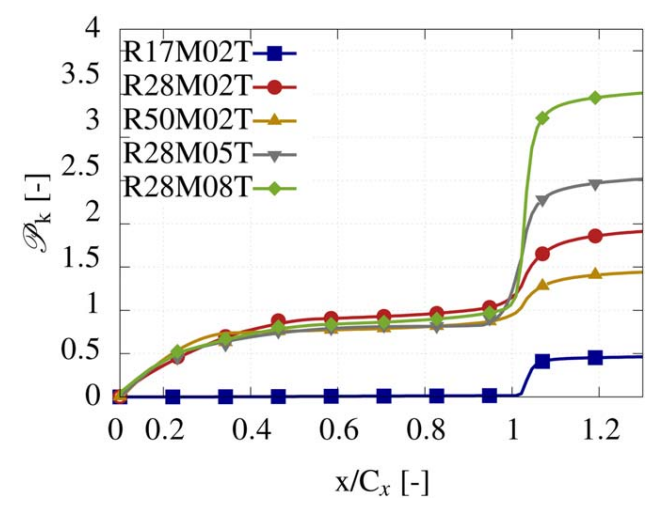

Fig. 21 Accumulated TKE production along the blade and in the wake for the $6 \%$ FST cases

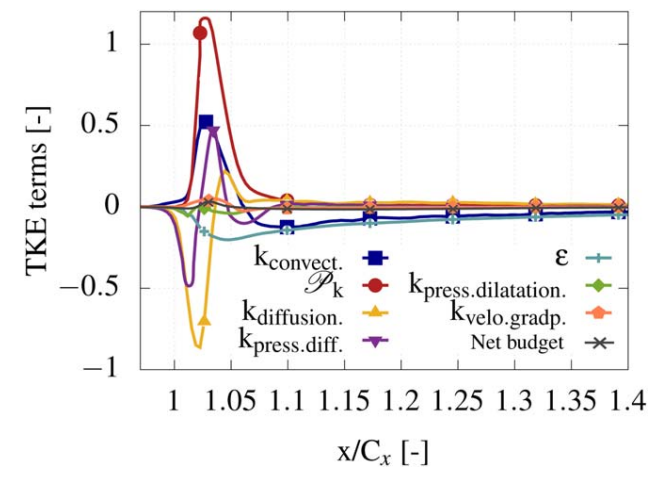

Fig. 22 TKE balance in the wake for the R28M02 case

balance are calculated on the fly during the simulation and stored to build the temporal averaging $\langle$.$\rangle and Favre-averaged quanti-$ ties [.]. 800 snapshots evenly distributed over the ten flow-through period have been used to build the temporal averaging and guarantee that two consecutive snapshots are decorrelated and differ from a more common practice where the temporal averaging is built over a large number of snapshots and a few time-steps between two snapshots. To check this statistical averaging procedure and convergence, a moving average has been used along time and checked until the axial evolution of the different terms of the TKE budget was not impacted. For the turbulent dissipation, both the resolved and subgrid scale contributions have been taken into account. The different terms of the TKE balance are integrated over axial subdomains of characteristic length $\mathrm{dx}$. This approach differs from common practices where the different TKE contributions are observed at different axial locations in a line normal to the wake $[11,65,66]$. The purpose is here to follow the evolution of the TKE contributions in the axial direction similar to the evolution of losses in the domain presented in Sec. 5. A local balance of the different terms composing the TKE budget is provided in Fig. 22 for the R28M02 case. In addition, the net budget of the TKE equation, i.e. the right-hand side of the TKE equation subtracted to the left-hand side term, has been added to this same figure to check the closure of the TKE budget. For a considered axial cut, the unbalance in the TKE budget is shown to remain below $4 \%$ with the largest unbalance observed where the TKE terms largely vary between $x / C_{x}=1.0$ and $x / C_{x}=1.05$.

For 0\% FST cases, since no turbulent activity is observed before the TE region, this analysis is restricted to the wake. The main contributions to the TKE balance are the turbulent production $\left(\mathscr{P}_{k}\right)$ and diffusion $\left(k_{\text {diffusion }}\right)$ with convection $\left(k_{\text {conv }}\right)$, dissipation $(\varepsilon)$, and turbulent pressure diffusion $\left(k_{\text {press.diff. }}\right)$ following. The pressure-dilatation $\left(k_{\text {press.dilatation. }}\right)$ and velocity fluctuation-pressure gradient correlation $\left(\mathrm{k}_{\text {velo.gradp. }}\right)$ increasing with the Ma are the two terms with a lower amplitude. The contributions to the TKE balance for the different cases at 0\% FST are shown in Figs. 23-26 where the

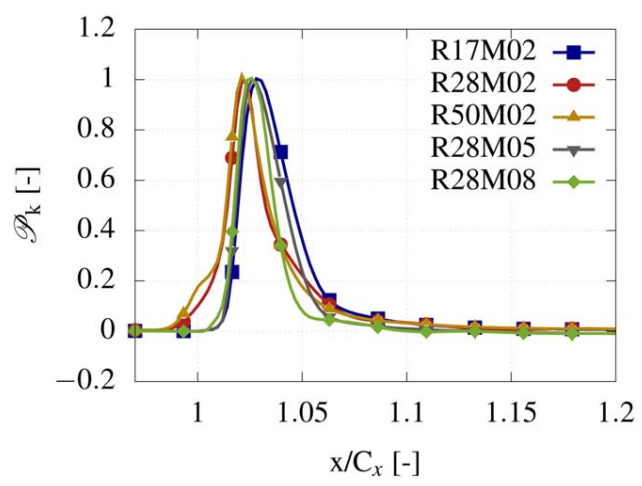

Fig. 23 TKE production in the wake for the 0\% FST cases 


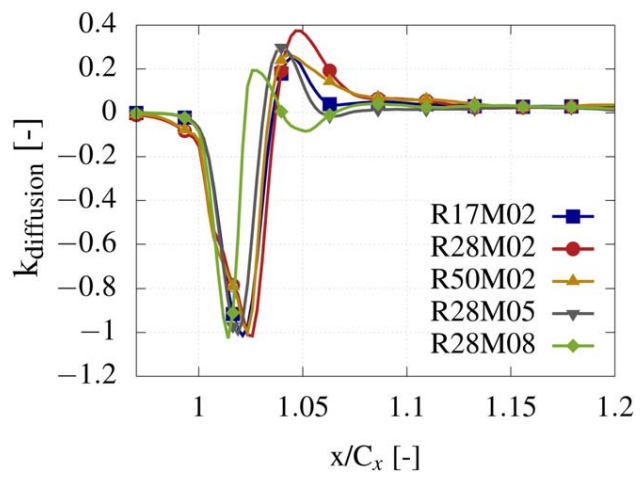

Fig. 24 TKE diffusion in the wake for the $0 \%$ FST cases

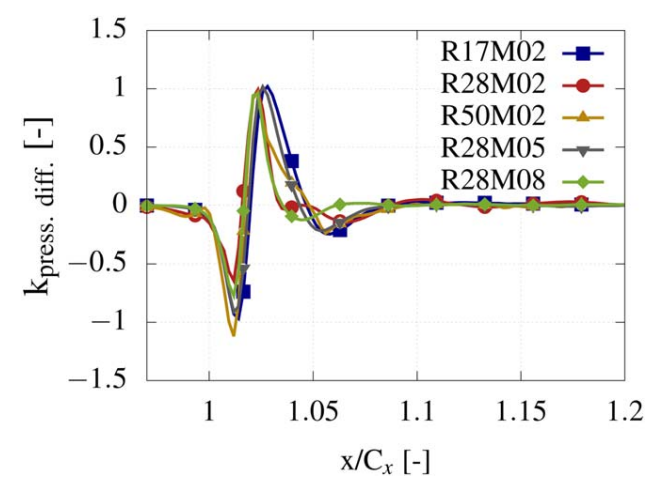

Fig. 25 Pressure diffusion of TKE in the wake for the $0 \%$ FST cases

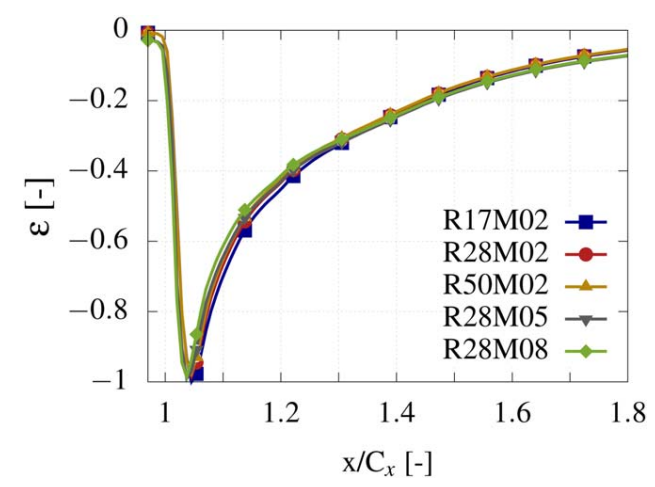

Fig. 26 TKE dissipation $(\varepsilon)$ in the wake for the $0 \%$ FST cases

values are normalized by their minimum/maximum value to compare more easily the different cases. The TKE production term corresponds to the extraction of mean flow energy at a relatively large turbulent scale and is always positive for the turbulence balance. Figure 23 shows the TKE production in the wake region for the $0 \%$ FST cases. The TKE production occurs mainly very close to the TE with a sharp increase from $x / C_{x}=1.0$ to $x / C_{x}=$ 1.03 , where it reaches a peak production. Then, the TKE production decreases to becomes negligible at $x / C_{x}=1.05$. The TKE diffusion and pressure diffusion terms shown in Figs. 24 and 25, respectively, display a similar behavior with a non-constant sign. Some energy is taken from the TKE between $x / C_{x}=1$ and 1.04 before to provide some energy to the turbulence between $x / C_{x}=1.04$ and 1.1. The distribution between positive and negative contribution is rather balanced for the pressure diffusion term while negatively oriented for the turbulent diffusion term. Similar to the TKE production, these two contributions become negligible after $x / C_{x}=1.1$.

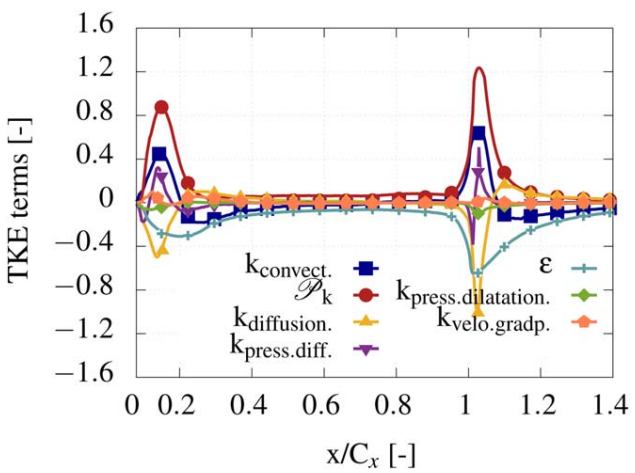

Fig. 27 TKE balance along the blade and in the wake for the R28M02T case

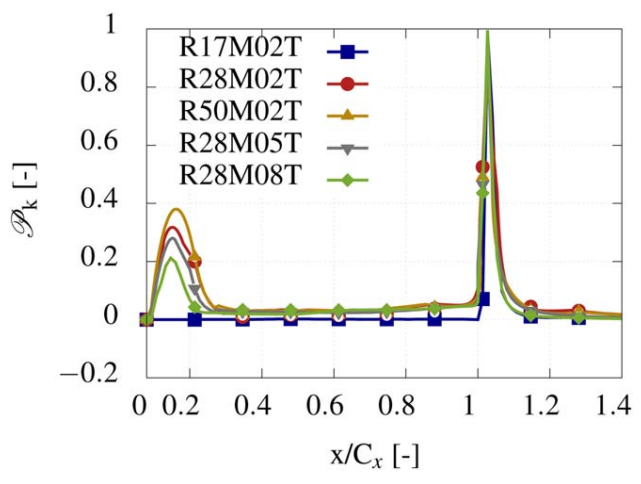

Fig. 28 TKE production along the blade and in the wake for the $6 \%$ FST cases

The TKE dissipation in the wake region for the 0\% FST is shown in Fig. 26. The TKE dissipation is always a negative term in the TKE balance and represents the transfer from TKE to internal energy mainly performed at small scales. The dissipation sharply increases from the TE until $x / C_{x}=1.05$. Unlike other terms, the decrease is made over a much longer distance and becomes negligible after around $x / C_{x}=1.5-2$. The Re/Ma has a marginal influence on the behavior of the different terms of the TKE balance except a balance shifted toward the TE at higher Ma. Also in terms of level, similar to the TKE production shown in Sec. 5 about the losses generated, the levels are higher when the Re is decreased and the Ma increased.

For the 6\% FST cases, Fig. 27 shows the different terms of the TKE balance for the R28M02T case. In the wake, the different terms behave similarly to the $0 \%$ FST cases. Along the blade, the

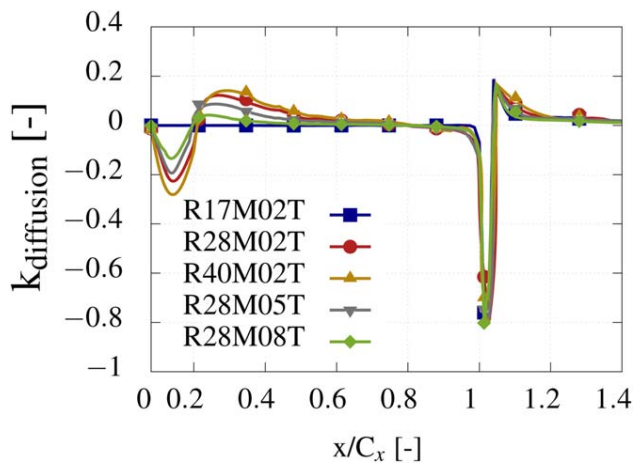

Fig. 29 TKE diffusion along the blade and in the wake for the $6 \%$ FST cases 


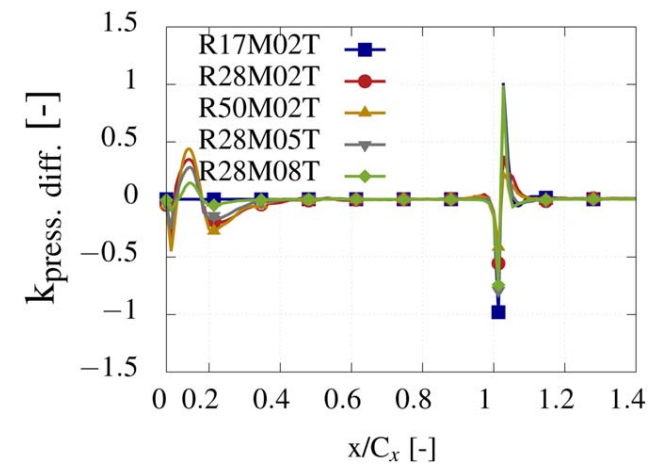

Fig. 30 Pressure diffusion along the blade and in the wake for the $6 \%$ FST cases

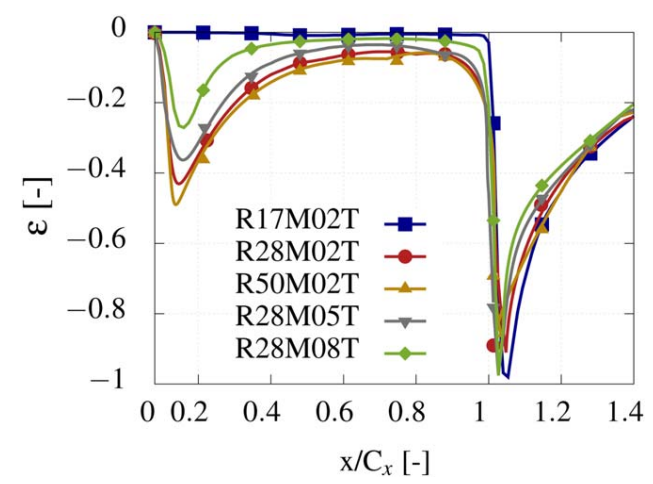

Fig. 31 TKE dissipation $(\varepsilon)$ along the blade and in the wake for the $6 \%$ FST cases

different terms sharply increase close to the LE before to recover marginal values along the blade. Gourdain [58] observed a similar sharp increase of the TKE energy at the transition location on a compressor blade row before to recover relatively low values of TKE behind the transition location. The TKE production sharply increases close to the LE and more moderately along the remaining of the blade before to increase sharply in the wake (see Fig. 28). The turbulent diffusion and pressure diffusion terms for the $6 \%$ FST cases along the blade and in the wake are shown in Figs. 29 and 30, respectively. The turbulent diffusion and pressure diffusion are also mainly triggered close to the LE and are active until $x / C_{x}=0.6$ for the diffusion and $x / C_{x}=0.4$ for the pressure diffusion. For the TKE dissipation term shown in Fig. 31 for the $6 \%$ FST cases, similar to the wake, the dissipation mainly increases close to the LE, but the dissipation process remains active until the throat at $x / C_{x}=0.8$.

\section{Conclusion}

The influence of the Re, Ma, and freestream turbulence has been conducted on the midspan flow of a configuration representative of an LPT using LES.

The pressure coefficient around the blade is relatively insensitive to the Re for the range considered. The increase of the Ma promotes a lower pressure coefficient before the throat on the blade suction side. For the cases where inlet turbulence was prescribed, a similar behavior of the flow to $\mathrm{Re}$ and $\mathrm{Ma}$ variations can be observed with a marginal additional pressure coefficient on the blade suction side.

In the near-wall region, for the same boundary layer state, the boundary layer is more prone to separate when the Re is increased on the blade suction side while delayed when the Ma is increased. The upstream turbulence promotes the transition of the boundary layer for the mid and high higher Re considered and prevents a boundary layer separation close to the trailing edge.

The TKE budget performed over axial cuts in the domain shows that in the wake region, the TKE production and diffusion are dominant terms in the balance. The different terms are mainly triggered close to the TE except for the TKE dissipation occurring over a larger axial distance. This trend is relatively insensitive to $\mathrm{Re}$ or Ma modification. The freestream turbulence induces the boundary layer to become turbulent for the two higher Re values, and the two main regions of turbulence activity are the transition point on the blade close to the LE and in the wake.

\section{Acknowledgment}

The authors are thankful to Safran Aicraft Engines (Eric Lippinois) for technical support and having funded this research project. Numerical postprocessing has been performed using the free python-based Library Antares. Part of this work was performed using HPC resources from GENCI - [CCRT-CINES-IDRIS] (Grant 2019-[A0042A06074]). Experimental data were obtained within the EU research project Main Annulus Gas Path Interactions (MAGPI), AST5-CT-2006-030874.

\section{Conflict of Interest}

There are no conflicts of interest.

\section{Date and Availability Statement}

The datasets generated and supporting the findings of this article are obtainable from the corresponding author upon reasonable request. The authors attest that all data for this study are included in the paper. Data provided by a third party listed in Acknowledgment. No data, models, or code were generated or used for this paper.

\section{Nomenclature}

\section{Latin Symbols}

$$
\begin{aligned}
c & =\text { curvilinear abscissa } \\
h & =\text { spanwise length } \\
k & =\text { turbulent kinetic energy } \\
p & =\text { pressure } \\
r & =\text { specific gas constant } \\
t & =\text { time } \\
u & =\text { velocity } \\
H & =\text { shape factor } \\
R & =\text { cross-correlation } \\
T & =\text { temperature } \\
\dot{m} & =\text { mass flowrate } \\
C_{f} & =\text { friction coefficient } \\
C_{x} & =\text { axial chord-length } \\
C_{p} & =\text { pressure coefficient } \\
\mathscr{P}_{k} & =\text { turbulent kinetic energy production } \\
\mathrm{Pr} & =\text { Prandtl number } \\
\mathrm{Tu} & =\text { turbulence intensity } \\
(x, y, z) & =\text { cartesian coordinates }
\end{aligned}
$$

\section{Greek Symbols}

$$
\begin{aligned}
& \alpha=\text { incidence, } \tan ^{-1}\left(u_{y} / u_{x}\right) \\
& \beta=\text { Clauser parameter } \\
& \gamma=\text { heat capacity ratio } \\
& \delta=\text { boundary layer thickness } \\
& \epsilon=\text { turbulent dissipation } \\
& \zeta=\text { total pressure loss coefficient } \\
& \eta=\text { Kolmogorov length scale } \\
& \theta=\text { momentum thickness }
\end{aligned}
$$


$\mu=$ dynamic viscosity

$\rho=$ density

$\tau=$ shear stress

$\nu=$ kinematic viscosity

$\Phi=$ viscous dissipation

\section{Subscripts and Superscripts}

edge $=$ boundary layer edge quantity

in/out $=$ inlet/outlet conditions

tot $=$ total

turb $=$ turbulent

$\mathrm{w}=$ wall

\section{Operators}

$$
\begin{aligned}
\dot{\dot{\tau}} & =\text { LES-filtered quantity } \\
\dot{\cdot} & =\text { Favre-filtered quantity } \\
\dot{+} & =\text { nondimensional wall distance } \\
\langle.\rangle & =\text { statistical averaging } \\
{[.] } & =\text { Favre averaging }
\end{aligned}
$$

\section{Appendix A: Domain Size in the Spanwise Direction and Imposed Periodic Boundary Conditions}

To check that the domain length in the spanwise direction is large enough to impose periodic boundary conditions, spanwise twopoint correlations are used. A set of probes aligned with the spanwise direction and at same abscissa $\left(0.5 C_{x}\right.$ downstream of the TE in the wake) is used to draw the cross-correlation for the axial $R_{u u}$, tangential $R_{v v}$, and normal velocity $R_{w w}$. Figure 32 shows the cross-correlation in the spanwise direction for these different velocity components. The different components of the cross-correlation fall off to zero values for a distance between probes larger than $0.4 \mathrm{~h}$ for the $R_{v v}$ and $R_{w w}$ correlations and larger than $0.55 \mathrm{~h}$ for the $R_{u u}$ correlation. In the spanwise direction, this observation supports a computational domain width sufficiently large to have coherent structures without forcing due to the periodic boundary conditions applied.

\section{Appendix B: Mesh Dependency}

The assessment of the grid convergence is made by comparing the friction coefficient on the blade suction side and the evolution of the TKE production $\left(\mathscr{P}_{k}\right)$ and dissipation $(\varepsilon)$ in the wake region for two level of mesh refinement and the R28M02 case. The first mesh is the one used during the study (standard) and a second refined mesh (fine). The fine mesh has been refined by decreasing all three near-wall characteristic lengths: $\Delta x^{+}, \Delta z^{+} \leq$ 15 , and $\Delta y^{+} \leq 0.8$. The mesh is also refined in the wake region to approach the Kolmogorov scale $\eta$ by satisfying the condition $(\Delta x \Delta y \Delta z)^{1 / 3}<10 \eta\left(0.0015 C_{x}\right)$. The fine mesh is composed of

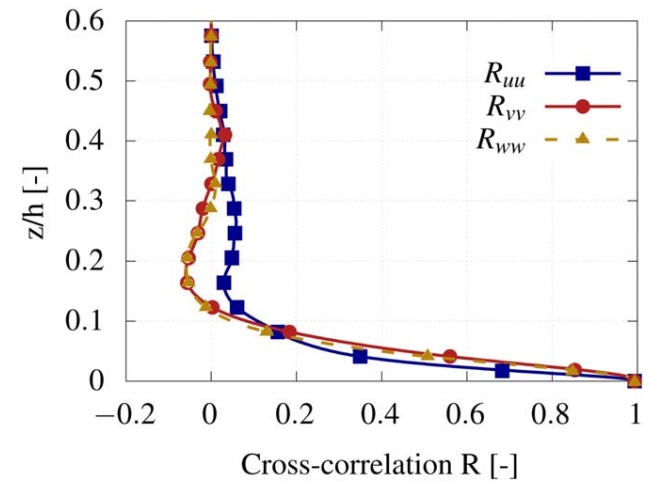

Fig. 32 Cross-correlation $R$ along the span of the blade $h 0.5 \mathrm{C}_{\mathrm{x}}$ downstream of the blade TE
Table 3 Summary of the meshes used for the study

\begin{tabular}{llll}
\hline \hline Mesh & Near-wall, wake & Cases & Mesh size \\
\hline Standard & $\Delta x^{+}, \Delta z^{+} \leq 25$, & R17M02 & \\
& $\Delta y^{+} \sim 1-2$, & R28M02 & \\
& $(\Delta x \Delta y \Delta z)^{1 / 3}<15 \eta$ & R50M02 & $100 \times 10^{6}$ \\
& & R28M05 & \\
Fine & $\Delta x^{+}, \Delta z^{+} \leq 15$, & R28M08 & \\
& $\Delta y^{+} \leq 0.8$, & R28M02 & \multirow{2}{*}{$350 \times 10^{6}$} \\
& $(\Delta x \Delta y \Delta z)^{1 / 3}<10 \eta$ & & \\
\hline \hline
\end{tabular}

around $350 \times 10^{6}$ cells compared to the $100 \times 10^{6}$ cells mesh used for the study. Table 3 gathers the main information about the two meshes. Figure 33 shows the friction coefficient for the standard and refined mesh on the blade suction side for the R28M02 case. The increase of the friction coefficient for the fine grid is slightly shifted compared to the standard grid and is marginally lower along the blade with a maximum discrepancy of around $1 \%$. The position where the $\mathrm{Cf}$ cancels agrees well for the two meshes. For the turbulent quantities, the TKE production in the wake does not show any influence of the grid refinement. The TKE dissipation is lower compared to the refined mesh (see Fig. 34). Also, for the fine mesh, the unbalance in the wake TKE budget was shown to be reduced compared to the standard grid, while the different terms of the TKE balance were observed to be relatively insensitive to the grid refinement except the turbulent dissipation $\epsilon$. As stated by Pichler et al. [2], this inbalance may be associated with the subgrid scale terms generated by the filtering of the equations in LES and the difficulty in accounting for the subgrid scale

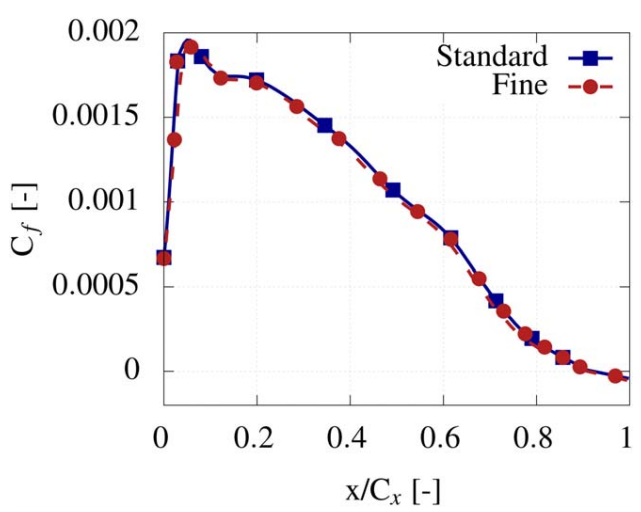

Fig. 33 Comparison of friction coefficient on the blade suction side based on the standard and refined mesh for the R28M02 case

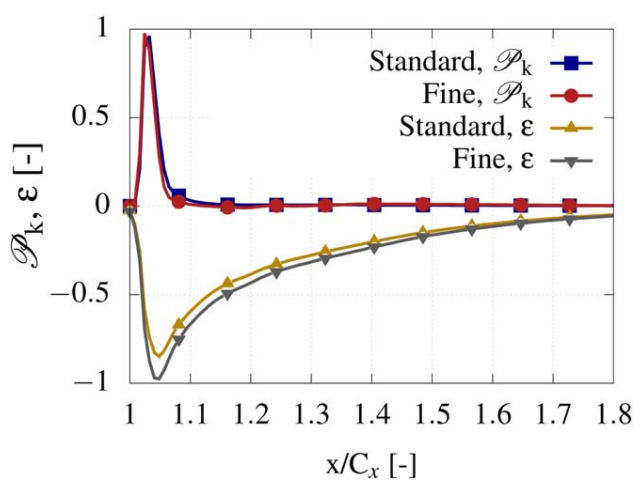

Fig. 34 Comparison of TKE production $\left(\mathscr{P}_{k}\right)$ and dissipation $(\varepsilon)$ based on the standard and refined mesh for the R28M02 case 
dissipation [67, 68]. From these observations, the mesh can be considered as sufficiently refined for mean flow quantities, and some care needs to be accounted for the turbulent quantities especially quantities related to small scales structures described in the study.

\section{References}

[1] Hourmouziadis, J., 1989, "Aerodynatmic Design of Low Pressure Turbines," AGARD Lecture Ser., 167(167), pp. 120-133.

[2] Pichler, R., Sandberg, R. D., and Michelassi, V., 2016, "Assessment of Grid Resolution Requirements for Accurate Simulation of Disparate Scales of Turbulent Flow in Low-Pressure Turbines," Proceedings of the ASME Turbo Expo, Seoul, South Korea, June 13-17, pp. 120-132.

[3] Tucker, P. G., Eastwood, S., Klostermeier, C., Jefferson-Loveday, R., Tyacke, J., and Liu, Y., 2010, "Hybrid LES Approach for Practical Turbomachinery Flows: Part 2-Further Applications," ASME Turbo Expo 2010: Power for Land, Sea and Air, Glasgow, UK, June 14-18, p. 2.

[4] Simon, F., and Ashpis, D., 1996, "Progress in Modeling of Laminar to Turbulent Transition on Turbine Vanes and Blades," Technical Report, Report No. NASA TM 107180, National Aeronautics and Space Administration, Washington, DC.

[5] Hodson, H. P., and Howell, R. J., 2000, "Unsteady Flow: Its Role in the Low Pressure Turbine," The 9th International Symposium on Unsteady Aerodynamics, Aeroacoustics and Aeroelasticity of Turbomachines (ISUAAT) and Legendre Lecture Series: Ecole Centrale de Lyon, Lyon, France, Sept. 4-8, pp. $1-33$.

[6] LaGraff, J., and Ashpis, D., 1998, "Minnowbrook II 1997 Workshop on Boundary Layer Transition in Turbomachines," Nasa Contractor Report, Aug. 20-23, Syracuse University Minnowbrook Conference Center, New York.

[7] Schulte, V., and Hodson, H. P., 2011, "Unsteady Wake-Induced Boundary Layer Transition in High Lift LP Turbines," ASME J. Turbomach., 120(1), pp. 28-35.

[8] Hodson, H. P., and Howell, R. J., 2005, "Blade Row Interaction, Transition, and High-Lift Airfoils in Low-Pressure Turbine," Annu. Rev. Fluid Mech., 37(1), pp. 71-98.

[9] Vera, M., Zhang, X. F., Hodson, H., and Harvey, N., 2007, "Separation and Transition Control on An AFT-Loaded Ultra-High-Lift LP Turbine Blade at Low Reynolds Numbers: High-Speed Validation," ASME J. Turbomach., 128(3), pp. 517-527.

[10] Montomoli, F., Hodson, H., and Haselbach, F., 2010, "Effect of Roughness and Unsteadiness on the Performance of a New Low Pressure Turbine Blade at Low Reynolds Numbers," ASME J. Turbomach., 132(3), pp. 132-141

[11] Michelassi, V., Chen, L.-W., Pichler, R., and Sandberg, R. D., 2014, "Compressible Direct Numerical Simulation of Low-Pressure Turbines Part II: Effect of Inflow Disturbances," ASME J. Turbomach., 137(7), pp. 122-134

[12] Hodson, H. P., and Howell, R. J., 2005, "The Role of Transition in High-Lift Low-Pressure Turbines for Aeroengines,” Prog. Aerosp. Sci., 41(6), pp. 419-454.

[13] Prakash, C., Cherry, D. G., Shin, H. W., MacHnaim, J., Dailey, L., Beacock, R., Halstead, D., Wadia, A. R., Guillot, S., and Ng, W. F., 2008, "Effect of Loading Level and Distribution on LPT Losses," Proceedings of the ASME Turbo Expo, Berlin, Germany, June 9-13, pp. 917-925.

[14] Kuerner, M., Reichstein, G. A., Schrack, D., Rose, M. G., Staudacher, S., Gier, J., and Engel, K., 2012, "Low Pressure Turbine Secondary Vortices: Reynolds Lapse Effect," ASME J. Turbomach., 134(6), p. 061022.

[15] Vázquez, R., Antoranz, A., Cadrecha, D., and Arma nanzas, L., 2006, "The Influence of Reynolds Number, Mach Number and Incidence Effects on Loss Production in Low Pressure Turbine Airfoils," ASME Turbo Expo 2006: Power for Land, Sea, and Air Volume 6: Turbomachinery, Parts A and B, Barcelona, Spain, May 8-11, ASME, pp. 949-960.

[16] Matsuura, K., and Kato, C., 2006, "Large-Eddy Simulation of Compressible Transitional Cascade Flows With and Without Incoming Free-Stream Turbulence," JSME Int. J., 49(3), pp. 660-669.

[17] Chernobrovkin, A., and Lakshminarayana, B., 1999, "Turbulence Modeling and Computation of Viscous Transitional Flows for Low Pressure Turbines," J. Fluids Eng., 4, pp. 555-566

[18] Suzen, Y. B., Huang, P. G., Hultgren, L. S., and Ashpis, D. E., 2003, "Predictions of Separated and Transitional Boundary Layers Under Low-Pressure Turbine Airfoil Conditions Using an Intermittency Transport Equation," ASME J. Turbomach., 125(3), pp. 455-464.

[19] Jones, W. P., and Launder, B. E., 1972, "The Prediction of Laminarization With a Two-Equation Model of Turbulence," Int. J. Heat Mass Transfer, 15(2), pp. 301314.

[20] Menter, F. R., Langtry, R., Völker, S., and Huang, P. G., 2005, "Transition Modelling for General Purpose CFD Codes," Procedings of the ERCOFTAC International Symposium on Engineering Turbulence Modelling and Measurements; ETMM6, Sardinia, Italy, May 23-25, pp. 23-46.

[21] Sagaut, P., 2006, Large Eddy Simulation for Incompressible Flows: An Introduction, Springer Science, New York.

[22] Tucker, P. G., 2011, "Computation of Unsteady Turbomachinery Flows: Part 2 LES and Hybrids,” Prog. Aerosp. Sci., 47(7), pp. 546-569.

[23] Germano, M., Piomelli, U., Moin, P., and Cabot, W. H., 1991, "A Dynamic Subgrid-Scale Eddy Viscosity Model," Phys. Fluids A, 3(7), pp. 1760-1765

[24] Piomelli, U., 1999, "Large-Eddy Simulation: Achievements and Challenges," Prog. Aerosp. Sci., 35(4), pp. 335-362.

[25] Lardeau, S., Leschziner, M., and Zaki, T., 2012, "Large Eddy Simulation of Transitional Separated Flow Over a Flat Plate and a Compressor Blade," Flow Turbul. Combust., 88(1), pp. 19-44.
[26] Michelassi, V., Wissink, J., and Rodi, W., 2002, "Analysis of DNS and LES of Flow in a Low Pressure Turbine Cascade With Incoming Wakes and Comparison With Experiments," Flow Turbul. Combust., 69(3-4), pp. 295-330.

[27] Michelassi, V., Wissink, J. G., Fröhlich, J., and Rodi, W., 2003, "Large-Eddy Simulation of Flow Around Low-Pressure Turbine Blade With Incoming Wakes," AIAA J., 41(11), pp. 2143-2153.

[28] Sarkar, S., 2008, "Identification of Flow Structures on a LP Turbine Blade Due to Periodic Passing Wakes," ASME J. Fluids Eng. 130(6), p. 061103

[29] Schuler, P., Dullenkopf, K., and Bauer, H.-J., 2011, "Investigation of the Influence of Different Rim Seal Geometries in a Low-Pressure Turbine," Volume 7: Turbomachinery, Parts A, B, and C, Vancouver, British Columbia, Canada, June 6-10, pp. 715-729.

[30] Schuler, P., 2016, "Einfluss der Rotor-Stator-Dichtung auf die Turbinenaerodynamik und Seitenwandkuhlung," Ph.D. thesis, Technical University Karlsruhe, Karlsruhe, Germany.

[31] Michelassi, V., Chen, L., Pichler, R., Sandberg, R., and Bhaskaran, R., 2016, "High-Fidelity Simulations of Low-Pressure Turbines: Effect of Flow Coefficient and Reduced Frequency on Losses," ASME J. Turbomach., 138(11), pp. 121-133.

[32] Lengani, D., Simoni, D., Pichler, R., Sandberg, R. D., Michelassi, V., and Bertini, F., 2018, "Identification and Quantification of Losses in a LPT Cascade by POD Applied to LES Data," Int. J. Heat Fluid Flow, 70(1), pp. 28-40.

[33] Wu, X., and Durbin, P. A., 2001, "Evidence of Longitudinal Vortices Evolved From Distorted Wakes in a Turbine Passage," J. Fluid Mech., 446(1), pp. 199228.

[34] Sedov, L. I., Friedman, M., Holt, M., and Cole, J. D., 1961, Similarity and Dimensional Methods in Mechanics, CRC Press, Boca Raton, FL

[35] Sandberg, R. D., and Michelassi, V., 2019, "The Current State of High-Fidelity Simulations for Main Gas Path Turbomachinery Components and Their Industrial Impact," Flow Turbul. Combust., 102(4), pp. 797-848.

[36] Sharma, O. P., Pickett, G. F., and Ni, R. H., 1992, "Assessment of Unsteady Flows in Turbines," ASME J. Turbomach., 114(1), pp. 79-90.

[37] Sharma, O. P., Ni, R. H., and Tanrikut, S., 1994, "Unsteady Flows in TurbinesImpact on Design Procedure," AGARD Lecture Series No. 195, Turbomachinery Design Using CFD, East Hartford, CT, May 1-4, pp. 1-44.

[38] Michelassi, V., Martelli, F., Dénos, D. J., Arts, T., and Sieverding, C. H., 1999, "Unsteady Heat Transfer in Stator-Rotor Interaction by Two-Equation Turbulence Model," ASME J. Turbomach., 121(3), pp. 436-447.

[39] Wu, X., Jacobs, R., Hunt, J. C., and Durbin, P. A., 1999, "Simulation of Boundary Layer Transition Induced by Periodically Passing Wakes," J. Fluid. Mech., 398(1), pp. 109-153.

[40] Coull, J. D., and Hodson, H. P., 2011, "Unsteady Boundary-Layer Transition in Low-Pressure Turbines,” J. Fluid Mech., 681(1), pp. 370-410.

[41] Gicquel, L. Y. M., Gourdain, N., Boussuge, J.-F., Deniau, H., Staffelbach, G., Wolf, P., and Poinsot, T., 2011, "High Performance Parallel Computing of Flows in Complex Geometries," Comptes Rendus Mécanique, 339(2-3), pp. 104-124.

[42] You, D., Wang, M., Moin, P., and Mittal, R., 2006, "Effects of Tip-Gap Size on the Tip-Leakage Flow in a Turbomachinery Cascade," Phys. Fluids, 18(10), pp. 305-316

[43] Gourdain, N., Sicot, F., Duchaine, F., and Gicquel, L., 2014, "Large Eddy Simulation of Flows in Industrial Compressors: A Path From 2015 to 2035," Phil. Trans. R. Soc. A, 372(2022), p. 20130323.

[44] Piomelli, U., 2008, "Wall-Layer Models for Large-Eddy Simulations," Prog. Aerosp. Sci., 44(6), pp. 437-446.

[45] Pichler, R., Zhao, Y., Sandberg, R. D., Michelassi, V., Pacciani, R., Marconcini, M., and Arnone, A., 2018, "LES and RANS Analysis of the End-Wall Flow in a Linear Low Pressure Turbine Cascade With Variable Inlet Conditions, Part I: Flow and Secondary Vorticity Fields," ASME Turbo Expo 2018: Turbomachinery Technical Conference and Exposition, Oslo, Norway, June 11-15, ASME, pp. 146-157.

[46] Wissink, J. G., and Rodi, W., 2006, "Direct Numerical Simulation of Flow and Heat Transfer in a Turbine Cascade With Incoming Wakes," J. Fluid Mech., 569(1), pp. 209-247.

[47] Lengani, D., Simoni, D., Pichler, R., Sandberg, R., and Michelassi, V., 2019, “On the Identification and Decomposition of the Unsteady Losses in a Turbine Cascade," ASME J. Turbomach., 141(3), pp. 111-121.

[48] Pope, S. B., 2000, Turbulent Flows, Vol. 1, Cambridge University Press, Cambridge.

[49] Smirnov, A., Shi, S., and Celik, I., 2001, "Random Flow Generation Technique for Large Eddy Simulations and Particle-Dynamics Modeling," ASME J. Fluids Eng., 123(2), pp. 359-371.

[50] Fontaneto, F., 2014, "Aero-Thermal Performance of a Film-Cooled High Pressure Turbine Blade/Vane: A Test Case for Numerical Codes Validation," Ph.D. thesis, University of Bergamo, Bergamo, Italy.

[51] Troth, L. S., 2017, "Multi-Physics Coupled Simulation of Gas Turbine," Ph.D. thesis, Cerfacs, Toulouse, France.

[52] Passot, T., and Pouquet, A., 1987, "Numerical Simulation of Compressible Homogeneous Flows in the Turbulent Regime," J. Fluid Mech., 181(1), pp. 441466.

[53] Colin, O., and Rudgyard, M., 2000, "Development of High-Order Taylor-Galerkin Schemes for LES,” J. Comput. Phys., 162(2), pp. 338-371.

[54] Lax, P. D., 1957, "Hyperbolic Systems of Conservation Laws II," Commun. Pure Appl. Math., 10(4), pp. 537-566.

[55] Nicoud, F., and Ducros, F., 1999, "Subgrid-Scale Stress Modelling Based on the Square of the Velocity Gradient Tensor," Flow Turbul. Combust., 62(3), pp. 183-200. 
[56] Mayle, R. E., 1991, "The Role of Laminar-Turbulent Transition in Gas Turbine Engines," Volume 5: Manufacturing Materials and Metallurgy; Ceramics; Structures and Dynamics; Controls, Diagnostics and Instrumentation; Education; IGTI Scholar Award; General, Orlando, FL, June 3-6, pp. $115-143$.

[57] Abu-Ghannam, B. J., and Shaw, R., 1980, "Natural Transition of Boundary Layers-The Effects of Turbulence, Pressure Gradient, and Flow History," J. Mech. Eng. Sci., 22(5), pp. 213-228.

[58] Gourdain, N., 2015, "Prediction of the Unsteady Turbulent Flow in an Axial Compressor Stage. Part 2: Analysis of Unsteady RANS and LES Data," Comput. Fluids, 106(1), pp. 119-129.

[59] Muppidi, S., and Mahesh, K., 2012, "Direct Numerical Simulations of Roughness-Induced Transition in Supersonic Boundary Layers," J. Fluid Mech., 693(1), pp. 28-56.

[60] Michelassi, V., and Wissink, J. G., 2015, "Turbulent Kinetic Energy Production in the Vane of a Low-Pressure Linear Turbine Cascade With Incoming Wakes," Int. J. Rotating Mach., 2015(2), p. 650783.

[61] Wheeler, A. P. S., Sandberg, R., Sandham, N. D., Pichler, R., Michelassi, V., and Laskowski, G., 2016, "Direct Numerical Simulations of a High-Pressure Turbine Vane Flow,” ASME J. Turbomach., 138(7), p. 071003.
[62] Lengani, D., Simoni, D., Ubaldi, M., Zunino, P., Bertini, F., and Michelassi, V., 2017, "Accurate Estimation of Profile Losses and Analysis of Loss Generation Mechanisms in a Turbine Cascade," ASME J. Turbomach., 139(12), pp. 121-132.

[63] Lengani, D., Simoni, D., Ubaldi, M., Zunino, P., and Bertini, F., 2017, "A POD-Based Procedure for the Split of Unsteady Losses of an LPT Cascade," Int. J. Turbomach. Propul. Power, 2(4), p. 17.

[64] Bogey, C., and Bailly, C., 2009, "Turbulence and Energy Budget in a Self-Preserving Round Jet: Direct Evaluation Using Large Eddy Simulation," J. Fluid Mech., 627(2), pp. 129-160.

[65] Pichler, R., Sandberg, R. D., Michelassi, V., and Bhaskaran, R., 2016 "Investigation of the Accuracy of RANS Models to Predict the Flow Through a Low-Pressure Turbine," ASME J. Turbomach., 138(12), pp. 121-132.

[66] Sideridis, A., Yakinthos, K., and Goulas, A., 2011, "Turbulent Kinetic Energy Balance Measurements in the Wake of a Low-Pressure Turbine Blade," Int. J. Heat Fluid Flow, 32(1), pp. 212-225.

[67] Vreman, B., Geurts, B., and Kuerten, H., 1997, "Large-Eddy Simulation of the Turbulent Mixing Layer," J. Fluid Mech., 339(1), pp. 357-390.

[68] Le Ribault, C., Sarkar, S., and Stanley, S., 1999, Large Eddy Simulation of a Plane Jet," Phys. Fluids, 11(10), p. 3069. 